\title{
ESTUDIOS
}

\section{Alejandro Korn Visto por sus Críticos}

\begin{abstract}
A cien años de su nacimiento y veinticinco de su muerte, la figura y A la obra de Alejandro Korn han originado ya una bibliografía abundante, aunque los títulos que la componen no son homogéneos en finalidad ni en significación. En este trabajo nos proponemos el análisis de esa bibliografía, análisis que puede servir para apreciar en qué medida el maestro argentino ha sido conocido, apreciado y criticado; y para saber cuánto se ha avanzado en la interpretación de su pensamiento y su acción, y cuánto falta lograr todavía.
\end{abstract}

Aunque nos referiremos a lo escrito sobre Korn, y no al pensamiento mismo del filósofo, se hace necesario proporcionar una imagen general de sus ideas filosóficas, de la que podrán prescindir sin pérdida los que conozcan en detalle la obra de Korn.

Nacido en r860 en San Vicente, pequeño pueblo de la pampa bonaerense, en un hogar de refugiados políticos alemanes del 48, Alejandro Korn comenzó su actividad profesional como médico de campaña en r883. Radicado en La Plata, donde vivió hasta el fin de su vida, fue profesor en el Colegio Nacional de la ciudad y diputado a la Legislatura de la Provincia de Buenos Aires. Durante casi veinte años fue director del Hospital de Alienados de Melchor Romero, cercano a La Plata. En I906 comienza su actividad como profesor de filosofía en la Universidad, de Buenos Aires, y diez años después abandona toda otra labor profesional para dedicarse exclusivamente a la enseñanza. Tenía entonces $5^{6}$ años y enseñaría durante 15 años más, en Buenos Aires y La Plata. En I930 se retira de la cátedra universitaria, aunque no de la labor docente en amplio sentido. Falleció en La Plata, en 1936, a los 76 años de edad.

La producción escrita de Korn no fue muy abundante. Hasta 1918 , 
contando ya 58 años y siendo entonces Decano de la Facultad de Filosofía y Letras de Buenos Aires, sólo había publicado algo más de una media docena de artículos. En ellos, sin embargo, estaban ya los temas y las principales ideas que desarrollaría más tarde. Los trabajos más representativos de su posición filosófica son los siguientes: "Incipit vita nova" (I9r8); "La libertad creadora" (r922); "Esquema gnoseológico" (1924); "El concepto de ciencia" (I926); "Axiologia" (1930). Estos trabajos fueron reunidos en un volumen titulado Ensayos filosóficos, publicado en 1930 en edición privada. Finalmente, en I935 aparecieron los Apuntes filosóficos, el único libro "público" aparecido en vida de Korn. Apuntes filosóficos contiene lo esencial de los trabajos anteriores aunque en una forma más sistemática, y agrega temas que no habían sido tratados anteriormente. Concebido como una "introducción a la filosofía" destinada a un público muy amplio, es al mismo tiempo un excelente resumen de la filosofía de Korn, escrito en los últimos días de su vida.

La obra escrita de Korn no se agota en los estudios mencionados. Sus ensayos sobre filósofos revelan, debajo de una claridad didáctica y una simplicidad de estilo que pueden resultar engañosas, una excepcional capacidad para hacer revivir en pocos trazos el núcleo de una filosofía. Korn dedicó también gran atención a la historia de las ideas en Argentina. Su obra Influencias filosóficas en la evolución nacional, en su mayor parte escrita a principios de siglo, sigue siendo clásica. Le ocuparon, además, los problemas universitarios de su época, sobre los que escribió varios artículos; la crítica de libros, ejercida no como mero instrumento de información, sino desde una posición definida ante la que comparecen las opiniones reseñadas; y el tema del socialismo, que le fue particularmente caro en los últimos años de su vida.

A comienzos de nuestro siglo se inicia en Argentina un cambio en la orientación filosófica de las cátedras. Frente al positivismo y al naturalismo imperantes, comienzan a actuar nuevas influencias: la "vuelta a Kant" primero, la filosofía de Bergson y la de Croce después. Es lo que se ha denominado la polémica antipositivista o etapa de superación del positivismo, que forma parte de un movimiento de renovación filosófica común a todos los países latinoamericanos. En r930 esta etapa puede darse por concluida, y esa fecha puede tomarse como el comienzo de un nuevo período, caracterizado por la influencia predominante de la filosofía alemana más reciente. Estas nuevas influencias encuentran el camino desbrozado por la acción de quienes combatieron al positivismo 
y trataron de ampliar él horizonte filosófico en los primeros treinta años del siglo. Entre ellos, la figura más importante es la de Alejandro Korn. La obra de Korn culmina, precisamente, hacia 1930.

El punto principal que separa a Korn del positivismo es el modo de concebir la libertad en la conducta humana. Si la conducta del hombre está determinada rigurosamente por su estructura biológica -o por cualquier otra forma de absoluta determinación- no hay lugar para la responsabilidad y, en consecuencia, la constitución de la ética es imposible. Por el contrario, nada interesa más a Korn que señalar la existencia de la libertad humana y mostrar que ella hace posible la ética. Más aún, para Korn el hombre es esencialmente el ejercicio de esa libertad. La cultura y la historia son sus consecuencias: la primera, como creación de formas culturales, desde la técnica hasta la moral; la segunda, como el drama de la tensión entre la libertad, que el hombre experimenta como su más preciosa esencia, y la coacción - la exterior de la naturaleza y la interior de los instintos-que se opone al cumplimiento de aquélla. El hambre es definido por Korn como el "animal rebelde": el símbolo prometeico es su símbolo. Constituido por su libertad, ha hecho de ella el instrumento para dominar la naturaleza, crear la técnica, elaborar la cultura y mejorarse moralmente. En este sentido afirma Korn que la libertad es libertad creadora.

El tema de la libertad, con implicaciones que aquí son omitidas, es, pues, el principal tema de Korn. Pero éste ha desarrollado también una posición gnoseológica, se ha ocupado especialmente del problema de los valores $y$, en medio de grandes reservas, ha incursionado en el terreno de la metafísica. La posición de Korn en teoría del conocimiento ha sido considerada por la mayoria de los críticos, y no sin razones para ello, como "idealista". Apoyan esta interpretación la crítica que Korn dirigió al realismo ingenuo y la importancia que concedió al hecho de que todo es dado en la conciencia y no es posible saber de la realidad sino a través de lo dado en la conciencia. Ahondando más en la gnoseología de Korn ésta of rece problemas más complejos a la interpretación, paro basta a nuestros fines destacar los rasgos señalados.

Korn hace de la axiología o teoría de los valores el objeto de la filosofía. De la realidad exterior se ocupan la ciencia - cuando es posible representar esa realidad en expresiones matemáticas-y las teorías - cuando el saber correspondiente no puede alcanzar ese nivel de exactitud. Del sujeto y sus reacciones valorativas se ocupa la filosofia, que es, por lo tanto, teoría de los valores. Korn realizó una clasificación y 
una descripción de los valores, dentro del marco de una axiología relativista.

Fuera de la filosofia, y aun casi fuera del saber comprobable y comunicable, se halla la metafísica. Al mismo tiempo que reconoce el carácter ineludible de las cuestiones metafísicas, Korn afirma la imposibilidad de constituir la metafísica como un saber objetivo. Sin embargo, aunque sostuvo que toda construcción metafísica sólo tiene valor para el que la crea (y a este respecto gustaba confundir los verbos creer y crear), aquí y allá asoman en sus escritos atisbos de una metafísica personal.

Por último, hay que advertir que la confianza de Korn en la capacidad de la razón era limitada. Consideraba que la elaboración racional de los datos de la experiencia es el único saber legítimo. Pero esta elaboración termina, según Korn, en oposiciones conceptuales irreductibles, en antinomias insalvables. La consecuencia que debemos extraer de ello no es, sin embargo, la pasividad escéptica. Por el contrario, la salida es la acción. La acción, para Korn, "corta el nudo gordiano" de las perplejidades teóricas. La historia nos muestra que, a pesar de las dudas eternas, nuestros antecesores se elevaron cada vez más por encima de la animalidad y crearon por medio de la acción el mundo de objetos y valores que hoy constituyen nuestra cultura. La acción es el modo de concretar la libertad creadora. "Al principio fue la acción", dice Korn; pero no quiete decir "al principio de las cosas", sino "al principio de la redención humana".

Se ha dicho muchas veces, pero es forzoso repetirlo, que Korn fue, ante todo, una extraordinaria personalidad. Más allá de su pensamiento filosófico considerado en un sentido técnico, o aun de la totalidad de su obra escrita, hay que destacar su influencia determinante en la creación de un ambiente filosófico, su alta calidad de maestro, su ejemplo de autenticidad nacional sin pétdida de las esencias universales. $Y$ todo ello no como aspectos separables, sino como manifestación unitaria de su irradiación espiritual. Alejandro Korn es, para la Argentina, una de esas raras personalidades que constituyen el más alto patrimonio de un pueblo, hacia las cuales siempre puede volverse como a una fuente de inextinguible energía moral.1

1 Para mayores detalles sobre el pensamiento de Korn véase la bibliografía de este artículo. Para la posición de Korn en la etapa antipositivista véase, entre otros, Francisco Romero, Sobre la filosofía en América (Buenos Aires, Raigal. 1952) y Juan Carlos Torchia-Estrada, La filosofía en la Argentina (Washington, D. C.. Unión Panamericana, 1961). 


\section{Difusión de Korn antes de su MUerte}

Durante la vida de Korn sus escritos no tuvieron gran difusión, y ello se explica por varios motivos. Como ya adelantamos, Korn comenzó a escribir más bien tarde y no escribió mucho. Cuando lo hizo, lo hizo con alguna reticencia, como quien carece de ambiente propicio. Lo que se dice un libro formal no lo publicó hasta los setenta años, y eso en edición privada. Además, su tipo espiritual lo llevaba a prodigarse en el círculo íntimo más que a buscar forma alguna de popularidad. Por último, escribió llana y modestamente, y todo él era una magnífica expresión de modestia científica. Estas virtudes, es sabido, no son las más apropiadas para el éxito del momento.

La primera mención que conocemos sobre un trabajo de Korn se publicó en la Revista de Filosofía, de Buenos Aires, que dirigía José Ingenieros. ${ }^{2}$ Se trata de una breve nota que resume un artículo sobre "Las ideas filosóficas en la historia argentina", que Korn habría publicado en la revista Actividad, de La Plata, en I9I6. No hemos visto el artículo a que se refiere la nota, pero, al parecer, a su vez reproducía una conferencia. Como entre I9I2 y I9I4 Korn llevaba publicado lo que luego serían los tres primeros capítulos de su libro Influencias filosóficas en la evolución nacional, presumimos que el artículo resumiría esos estudios. La nota llevaba las iniciales M. K. (75).$^{3}$

Como se recordó, en 1930 apareció la edición privada de los Ensayos filosóficos, el libro en el cual Korn recogió las expresiones más personales de su pensamiento filosófico, ante la certeza de que nunca les daría un desarrollo sistemático acabado. Conocemos dos artículos publicados con motivo de este libro. Uno apareció en la revista Nosotros, escrito por Delfina V.D. de Ghioldi, y era más bien una reseña expositiva (47). El otro se publicó en Humanidades, de La Plata, y fue su autor el profesor José A. Rodríguez Cometa. El artículo de Rodríguez Cometa era una exposición y, al mismo tiempo, una crítica escrita con

2 Por ello no está en lo cierto León Dujovne cuando afirma, en un artículo reciente (cf. núm. 33 de la bibliografía de este artículo), que una nota suya redactada con motivo de la publicación de "La Libertad creadora", aparecida en La Nación en 1922, fue lo primero que se publicó scbre Korn.

3 Para evitar la multiplicación de datos bibliográficos y de notas a pie de página, cada vez que hagamos referencia a un trabajo sobre Korn lo representaremos, entre paréntesis y dentro del texto, por el número de entrada que tiene en la bibliografía que va al final de este artículo. Si se trata de una cita agregaremos, a continuación del número de referencia, la indicación sobre la página en que se encuentra el texto citado. 
afecto y respeto. Uno de los puntos que más preocupaban al crítico era el relativismo de Korn en el terreno de los valores (I03).

Ya muy cercana la muerte del maestro, en el número de julio de 1936 de la revista Nosotros se publicaron dos breves fragmentos de estudios - redactados con anterioridad- de Francisco Romero y Alberto Rougès, respectivamente. El de Rougès se titulaba "Aproximación a Korn", y en él se destacaba la preocupación del filósofo por los problemas del conocimiento (I26). Romero aludió en su trabajo al escaso reconocimiento público que la labor de Korn había suscitado hasta entonces. Refiriéndose al retiro de Korn de la actividad universitaria escribió Romero: "Casi nadie reparó en que una de las más puras y nobles figuras universitarias de la Argentina se alejaba de las aulas, después de consagrar a ellas media vida de actividad intensa y ejemplar; al parecer, Don Alejandro Korn carecía de los requisitos indispensables para que tal suceso ocupase la atención de la gente" (107, p. 462). "Por estos y otros motivos afines -çontinuaba Romero- el nombre de Korn no tiene la difusión que se merece. Ajeno a cualquier manejo dudoso, irreductible, rebelde hasta a ese artificial empaque, estiramiento o estilización de la figura que es entre nosotros aliciente para la notoriedad, Alejandro Korn ha sido siempre y sigue siendo un hombre al margen. Y sin quererlo, por la misma fuerza de las cosas, esta situación suya califica en cierto modo todo aquello a cuyo margen queda él" (107, p. 464).

El resto de este trabajo mostrará cómo Alejandro Korn fue dejando de ser una figura marginal, para ser reconocido al fin como uno de los principales pensadores latinoamericanos.

2. LA PRIMERA AGRUPACIÓN DE SUS ESCRITOS Y LOS ECOS INMEDIATOS DE SU MUERTE

En agosto de I934, dos años antes de morir, Korn escribió a León Dujovne: "Nunca me he preocupado de catalogar mis publicaciones. Ahi andan por revistas y periódicos, y no seré yo quien se preocupe de reunirlas" (33). Poco después aparecían los Apuntes filosóficos, que junto con los Ensayos filosóficos fueron los dos únicos libros que publicó. El resto de la obra quedó, en el momento de su muerte, disperso en publicaciones periódicas, como él mismo afirmó. De tal modo, su difusión, en escala nacional, comienza con la agrupación póstuma de sus escritos. Korn no alcanzó a ver la repercusión de su pensamiento.

A la editorial Claridad debe agradecerse el primer intento de reunir 
los escritos de Korn en la serie "Obras de Alejandro Korn", que abrazó los siguientes títulos: Influencias filosóficas en la evolución nacional, Filósofos y sistemas, La libertad creadora, Ensayos críticos y, en segunda edición, Apuntes filosóficos. Aunque eran ediciones populares, cada uno de los volúmenes iba precedido de un prólogo o estudio preliminar, que es lo que ahora nos interesa.

La publicación de Influencias filosóficas en la evolución nacional proporcionó a Luis Aznar la oportunidad de of recer el primer esquema biobibliográfico del maestro (12). Las lineas de su cuadro biográfico se han mantenido, y los datos que entonces proporcionó sobre los escritos de Korn son el primer intento de una bibliografía que, completa y rigurosa, todavía no poseemos.

Francisco Romero antepuso a Filósofos y sistemas un ensayo en el que destacaba - como ha sido siempre la nota dominante en sus escritos sobre Kiorn- los valores humanos de la personalidad del filósofo argentino (rog). Parte de este ensayo había sido publicado anteriormente en el número de noviembre de 1936 de la revista Nosotros, al que ya aludimos.

"Alejandro Korn, maestro de saber y de virtud" se titulaba el trabajo - uno de los más completos que se han escrito sobre Korn-que Eugenio Pucciarelli puso como estudio preliminar al volumen $L a$ libertad creadora. Pucciarelli denominó "idealismo gnoseológico" (con lo cual seguramente queria determinar que este idealismo no tenía carácter metafísico) a la posición de Korn en teoría del conocimiento. Como lo haría mucho más tarde William Kilgore, vió como una consecuencia de ese idealismo la posición relativista de Korn, no sólo en gnoseología, sino también en teoría de los valores. "Agnosticismo y relativismo moral -ha escrito Pucciarelli- son consecuencias derivadas de aquellas premisas. Pero las dificultades que suscitan el conocimiento y la valoración se resuelven en la acción, aunque en la acción termina la filosofía (86, pp. I9-20). Sin embargo, nos recuerda el mismo autor, en la esfera de lo moral Korn no aceptó que el relativismo se volviera nihilismo. Por el contrario, la ética de Korn es afirmativa. Si bien la reunión de este carácter afirmativo con el relativismo moral puede levantar justas objeciones.

El volumen titulado Ensayos críticos fue prologado por Enrique Anderson Imbert (3). En breves páginas, Anderson Imbert proporciona ùna imagen fiel del estilo de pensamiento y de expresión literaria característicos de Alejandro Korn. Con el mismo cincel y con idéntica ac- 
titud, viene a decirnos el autor, Alejandro Korn modeló su vida, su filosofía y su prosa. También nos habla Anderson de cierta tensión interior que mantuvo a Korn entre la circunspección de su relativismo expreso y la pasión afirmativa de su fe en el valor de la libertad y la dig. nidad humanas.

Raimundo Lida prologó la segunda edición de los Apuntes filosóficos con un breve ensayo, finamente escrito, titulado "Korn o el filósofo prudente" (65). Destacó con acierto el lugar que lo ético tiene en el pensamiento de Korn y, considerando que "la difícil virtud del filósofo debe ser de ascetismo y prudencia", estimó que esa había sido la gran virtud de Korn. Digamos, apenas de paso, que si bien no es impropio llamar a Korn "filósofo prudente", quizá haya que añadir que esa prudencia fue expresión de algo más profundo: desconfianza de los alcances de la pura razón, fe limitada en las posibilidades de la filosofía.

Entre los comentarios que originaton estas ediciones destacamos el que Aníbal Sánchez Reulet dedicara, en la revista Nosotros, a Influencias filosóficas en la evolución nacional. "La primera historia de las in. fluencias filosóficas - escribió el mencionado crítico- ha sido hecha entre nosotros por Alejandro Korn. Con ser el primer intento - admirable, sin duda- es algo más que un intento. A pesar de sus imperfecciones es un trabajo excelente, vigoroso, irreemplazable" (I29, p. 345). Más allá del juicio sobre la obra en sí, Sánchez Reulet se refiere a la preacupación argentina de Korn en un pasaje que exige la transcripción en extenso: "En este libro, y en otros, Korn ha destacado siempre la peculiaridad de nuestro modo de pensar y sentir. Era uno de sus mayores afanes. Un poderoso sentimiento nacional y una fuerte voluntad política se entrecruzaban en su actitud teórica. Peto no eran incompatibles con la dignidad intelectual del filósofo. Las influencias filosóficas constituyen un momento necesario en el desarrollo de su personalidad. No responde a simple y ociosa curiosidad intelectual. Korn necesitaba conocer la evolución idiológica de su propio pueblo para tener la seguridad de cuál habría de ser su posición dentro de ella. ... Los motivos nacionales y políticos que se entrecruzaron en su posición teórica, y en cierto modo la condicionaron, constituyen, en verdad, un solo motivo: el de servir a la colectividad en que había nacido. El nacionalismo era, para Korn, algo más que un repertorio inerte de ritos: era el pensamiento, hondamente sentido, de una Argentina mejor. Y la política era para él, no un manejo indigno de apetitos, sino la realización de ese pensamien- 
to. Su voluntad política estaba, pues, traspasada de exigencias éticas, como lo estaba toda su teoría filosófica, su original pragmatismo de la libertad. Cuando la teoría sirve a esta política no se rebaja, se enaltece" (x29, Pp.346-347).4

En 1937 tuvo lugar en Buenos Aires el II Congreso de Historia de América. A él presentó Francisco Romero una ponencia titulada "Alejandro Kotn y el positivismo". En ella, como en otros artículos anteriores, adelantó Romero materiales que tomarian su forma definitiva en un ensayo que examinaremos más adelante. Del trabajo que aquí mencionamos nos interesa un asunto que Romero no ha tratado con la misma extensión en otros ensayos suyos sobre Korn: la relación de éste con ciertas corrientes de la filosofía contemporánea. En efecto, si se examinan los escritos de Korn sobre la filosofía contemporánea, se advierte que aquél otorga escasa importancia a ciertas tendencias recientes. Romero, buscando las causas de esta actitud, viene a decirnos en resumen: Korn combatió de frente al positivismo porque lo consideró un adversario digno; en cambio, a ciertas corrientes de la filosofía contemporánea (precisamente las que más influyeron después: Husserl, Scheler, Heidegger) no les prestó mayor atención porque las consideró expresiones de un neo-romanticismo que no arraigaría profundamente (IIO).

Con motivo de la muerte de Korn, el diario La Gaceta, de Tucumán, le rindió homenaje en su número del Iํ de enero de 1937. Allí Francisco Romero se refirió a los Apuntes filosóficos, considerándolos el "testamento filosófico" del maestro, pues el libro habia sido escrito cuando Korn ya estaba afectado por la enfermedad que provocaría su fallecimiento (108). En el mismo número Alfredo Coviello publicó un artículo titulado "Una página de historia en la naciente filosofía argentina", que en rigor era un examen del pensamiento de Korn en paralelo con el de José Ingenieros. Coviello veía en Ingenieros y Korn "los jefes

4. Influencias filosóficas en la evolución nacional originó otro comentario, publicado en la revista Claridad, y que citamos a manera de curiosidad. Después de destacar su autor los valores personales de Korn y su posición en el pensamiento argentino, anota algunas "deficiencias" en la obra, si ésta es examinada "con criterio de ortodoxo positivista, y aun sin mucha ortodoxia". Estas deficiencias, sin embargo, se explicarían por las fechas en que se escribieron los distintos capítulos, pues, salvo el último, todos son anteriores al giro final del pensamiento de Korn, "que ya en el ocaso de su vida se plegó con todo entusiasmo a la falange de los partidarios de la fecunda corriente de la filosofía positiva". Por obra de esta singular interpretación-que quizá confunde, en los últimos años de Korn, la adhesión al socialismo con la adhesión al positivismo-, llegaríamos a descubrir que, después de una vida dedicada a superar el positivismo, Alejandro Korn se habría convertido... al positivismo. Ello nos exime de todo comentario. (Véase el núm. 25 de nuestra bibliografía). 
visibles de dos movimientos filosóficos opuestos", es decir, el positivismo y el antipositivismo. Su paralelo, sin embargo, se atiene sólo a unos pocos puntos de similitud y diferencia entre ambos pensadores. En la consideración de Coviello, Korn representa, sobre todo, la defensa de la "filosofía en sî". La expresión, que podría prestarse a error, quiere significar que en Korn la filosofía no se da en una dependencia tan estrecha de la ciencia, como en el caso de Ingenieros, sino que tiene una estructura y una finalidad autónomas (28).

Naturalmente, no fue el de La Gaceta el único homenaje tributado a Korn con motivo de su muerte. Otras notas y noticias aparecieron en diversas publicaciones periódicas. ${ }^{5}$ Destacamos el artículo que Sánchez Reulet publicó en Sur, en 1937. "Fue el primer argentino-dijo de Korn-que estudió filosofía en serio, pero fue también el primero en hacerla" ( 130, p. 88).

En el mismo año Anderson Imbert publicó en La Nación, de Buenos Aires, un artículo titulado " $\mathrm{La}$ acción en Alejandro Korn". En él destaca el lugar que la acción tiene en el conjunto de las ideas de Korn, de acuerdo con los textos del filósofo; pero va más lejos, buscando el nexo entre lo que Korn afirma sobre la acción y su actitud como hombre entregado a ella. Para Korn, como ya recordamos, el pensar teórico termina en antinomias insolubles. Para evitar la total desilusión e inercia sólo hay un camino: deciditse por la acción. Como escribe Anderson Imbert, "en el momento de la acción decisiva Korn no toleraba los subterfugios de la teoría. ... Su consigna, pues, fue la acción". "Pero esta consigna -agrega- era, en verdad, una inconsecuencia de su teoría". Su afirmación rotunda sobre el valor de la acción -y de la libertad creadora - no se condice con su relativismo. "Korn se entregó a la acción porque era el mandato imperioso de su conciencia individual, porque su personalidad autónoma así lo quería, porque, para él, el valor supremo era lo ético. Esta fuerza de su carácter se mezclaba a veces, subrepticiamente, con su pensamiento teórico. Sus lectores reparan, a ratos, cómo su relativismo se traiciona a sí mismo ( 5 ). Se trata, pues, de una idea que ya habíamos encontrado en el prólogo a Ensayos críticos.

5 En efecto, entre los papeles que conserva la familia Korn, pudimos ver numerosas noticias y notas anónimas con motivo de la muerte del filósofo. 
3. De la edición oficial de sus "Obras" hasta el décimo aniverSARIO DE SU FALLECIMIENTO

La primera edición conjunta de sus escritos realizada por la editorial Claridad, los comentarios inspirados por ella y los ecos inmediatos de su muerte, convirtieron a Korn, en lo que al reconocimiento público se refiere, en una figura de relieve nacional. Pero ya en el mismo año de su fallecimiento la Universidad de La Plata decidió publicar la edición oficial de sus obras. Esta edición contribuyó mucho a que Korn fuera conocido en el extranjero, al cual su obra había trascendido poco hasta entonces. Se abre así un período, que abarca unos diez o doce años, en el cual la producción sobre Korn es intensa, tanto en la Argentina como fuera de ella, y al cabo del cual la obra de Korn tiene ya una difusión de amplitud americana.

Con el título de Obras y en edición a cargo de Francisco Romero, Eugenio Pucciarelli y Aníbal Sánchez Reulet, los escritos de Korn se publicaron en tres volúmenes, bajo el patrocinio de la Universidad de La Plata. El primero apareció en I938 y contenía los principales trabajos filosóficos de Korn - los que se habian publicado bajo el título de $E n$ sayos filosóficos en r930-y los Apuntes filosóficos. El segundo volumen se publicó un año más tarde e incluía los escritos de Korn sobre historia de la filosofia y filosofía contemporánea, además de algunas notas bibliográficas y cartas de interés filosófico. El tercer volumen apareció en 1940 , conteniendo Influencias filosóficas en la evolución nacional, otros escritos sobre filosofía en la Argentina y otras notas bibliográficas. La edición estaba precedida por un estudio de Francisco Romero, sobre el que volveremos enseguida, y el segundo volumen llevaba como apéndice una breve nota biográfica de Luis Aznat.

El trabajo de Romero al que acabamos de aludir es uno de los mejores que se han escrito sobre Korn y se ha reproducido varias veces. En el se aprovechan trabajos anteriores, que aquí logran su expresión más amplia y orgánica. Las páginas que Romero dedica a trazar la figura moral de Korn son irreemplazables. En cuanto a su filosofía, una de las tesis más originales de este trabajo es la afirmación de que en Korn se dio el proceso de superación del positivismo en coincidencia con el proceso europeo y no en dependencia de él. "Alejandro Korn-escribe Romero- en este rincón americano, ha vivido esta etapa de la historia de las ideas [la transición del positivismo a la renovación filosófica que le siguió] con una extraña similitud, que llega a veces a la identidad, 
respecto a los pensadores europeos. No ha sido su discípulo, ni mucho menos su eco, sino su par. La crisis que ocurrió en aquellos filósofos se repite punto por punto en él; los motivos que en ellos aparecen se reiteran en lo esencial en el filósofo argentino. ... Alejandro Korn ha encarnado aquí las mismas ansias de renovación filosófica que surgieron en Europa a fines del siglo anterior, y lo ha hecho por su cuenta, con sentido personal, con un profundo acento propio" (III, pp. I6-I7, edición Claridad). Y luego muestra cómo se dan en Korn los aspectos y preferencias que caracterizaron a la filosofía de la primera etapa postpositivista: el interés por la historia de la filosofía; la "vuelta" a Kant; el problema del conocimiento; y el problema de los valores. Entre estos aspectos queremos destacar ahora lo que Romero afirma sobre el interés de Korn por la historia de la filosofía. "La historia de la filosofía ha tenido en Korn - dice Romero- un estudioso de raras calidades; es difícil que en la América de nuestro idioma alguien haya proyectado su atención sobre el pasado filosófico con una comprensión más profunda, con inteligencia más amplia y perspicaz" (III, p. I8, edición Claridad).

En los años inmediatos a la edición de Obras publicada por la Universidad de La Plata —aproximadamente hasta I946- se publican numerosos trabajos sobre Korn. Como dejamos dicho, varios aparecieron fuera de Argentina. Don Alfonso Reyes publicó en El Nacionai, de México, un artículo titulado "Korn y la filosofía argentina", luego reproducido en Repertorio Americano. El artículo, de intención más bien informativa, además de dar una idea general sobre el pensamiento de Korn destaca especialmente su interpretación de la filosofía contemporánea y su inquietud por la creación de un pensamiento "nacional". Impresiona particularmente al expositor el hecho de que Korn no ejerza la crítica de los filósofos contemporáneos desde el exclusivo punto de vista teótico, sino que busque, en cada caso, la relación entre las ideas del filósofo y su actuación en su medio social. "Lo que más importa en esta sumaria revista -escribía Reyes- es la posición de Korn, su disgusto al convencerse de que ninguno de estos intentos [los de los pensadores contemporáneos estudiados] corresponde a la realidad social del pais que los vió nacer, y aquella cierta impaciencia, bien notoria en los casos de Gentile y Heidegger, con que somete Ia teoría del filósofo al contraste 'de su conducta como hombre. Se diría que para él la filosofía debe ser, ante todo, una ética social y una ética individual" (94, p. 26).

En Cuba se ocupó de Korn, en un artículo publicado en I940 en la Revista Cubana, Medardo Vitier. Escrito con simpatía, el trabajo de 
Vitier está bien elaborado, en cuanto a las noticias que contiene y en cuanto a la exposición general. No resume todas las ideas filosóficas de Korn, sino las que considera más salientes. Vitier percibió la capacidad de Korn para apresar en breves párrafos las notas características de una época o de una doctrina. Designa a la posición filosófica de Korn como voluntarismo o afirmación del primado de la voluntad sobre la razón. Parte del trabajo de Vitier es una comparación entre Korn y el pensador mexicano Antonio Caso ( 147 ).

En el mismo año de r940 apareció en la Revista lberoamericana un largo estudio de César Barja sobre Korn (I6). Al exponer la asimilación que Korn establece entre la filosofía y la axiología destaca Barja, al igual que otros críticos, la posición relativista del pensador argentino en lo que respecta a la teoría de los valores. Otros temas del pensamiento y la significación de Korn tratados por Barja son los siguientes: su lugar en la historia ideológica argentina en el momento de superación del positivismo; el tema de la libertad y el de la acción; y su posición ante la metafísica. Al tratar del papel que juega la acción en la filosofia de Korn, afirma nuestro autor que en el pensador argentino se conjugan dos actitudes vitales: el pesimismo y el optimismo. El primero provendría de la raíz europea del pensador, mientras que el segundo sería el resultado de su condición de espectador y ciudadano de un pais y un continente nuevos, dueños de un futuro promisorio. Finalmente, destaca Barja la circunspección de Korn frente al problema metafísico. La "honradez máxima" de Korn le impidió dar como verdad de conocimiento sus últimas convicciones metafísicas: "no dio como filosofía ni menos como ciencia lo que sabía que no lo era; aceptó sencillamente la que estimó ser la verdad del caso. La verdad de razón, única que en el pensar filosófico debía contar" ( I G, p. 364).

Un poco más tarde la obra de Korn alcanza difusión en lengua inglesa. Eran los años en que Edgar Sheffield Brightman, gran amigo de la filosofía latinoamericana, escribía periódicamente en The Personalist sobre libros y autores de América Latina. En un artículo de 1943, titulado "Personalism in Latin America" se refirió a Korn afirmando que su influencia había creado un clima propicio al personalismo (19).

Difusión más amplia en la misma lengua obtuvo la figura de Karn a través del libro de Crawford, A Century of Latin American Thougbt, en el cual el filósofo argentino aparece junto con otros pensadores y escritores latinoamericanos del siglo pasado y del nuestro (30). Crawford destacó algunos puntos de la doctrina filosófica de Korn, sin que la ex- 
posición revelara una asimilación profunda de los textos. La posición que concede a Korn en el conjunto es también muy discutible. Comparando la extensión dedicada a otros argentinos, encontramos que las páginas consagradas a Manuel Gálvez doblan las dedicadas a Korn y el número de las que corresponden a Ingenieros es cuatro veces mayor. Aunque la cantidad de páginas no es un índice absoluto de atribución de importancia, la proporción mencionada resulta injusta, especialmente porque no hay ninguna afirmación o aclaración atenuante. José Gaos, que ha hecho una muy severa crítica del libro de Crawford, considera que Korn resulta en él "injustamente apreciado, o, con más exactitud, despreciado, relativamente más que ningún otro, hasta el punto de sentirlo intencionalmente rebajado" (45, p. I25). El juicio, aunque quizá excesivo en lo que se refiere a la intención, expresa la situación a que aludimos. Con todo, no puede negarse, desde el punto de vista de nuestro tema, la contribución del libro de Crawford a la difusión de Korn en los Estados Unidos, al colocarlo entre los autores representativos de Latinoamérica.

Debemos a W. Mann un penetrante análisis de las poesías de Korn, publicado en la revista Atenea, en octubre de I944, con el título de "El fondo ideológico de las poesías de Alejandro Korn" (7I). Las poesías analizadas son las editadas por el Instituto de Estudios Germánicos de la Universidad de Buenos Aires, en el original alemán y la traducción al castellano de Ernesto Palacio. No incluyen, por lo tanto, unos sonetos que se publicaron después de la muerte de Korn, y a los que nos referiremos más adelante. Mann hace muy atinadas observaciones sobre la influencia de Schopenhauer en el pensamiento de Korn, advirtiendo también los aspectos en que éste se separa del filósofo alemán, por el cual tenía gran estima. Aunque, hasta donde sabemos, el autor sólo escribió sobre Korn el trabajo que comentamos, evidencia gran penetración y muy buen conocimiento del pensador argentino. Entre otras observaciones, distingue en Korn dos "imágenes de la realidad humana": la poética y la filosófica - la expresada en sus poesías y la expuesta en sus escritos filosóficos-, y encuentra que "el momento que da unidad a ambas" es la libertad.

Otras expresiones del reconocimiento de Korn en el extranjero hacia esta época fueron su inclusión en la Antologia del pensamiento de lengua española en la edad contemporánea, de José Gaos (44), y en la obra del educador uruguayo "Jesualdo", Diecisiete educadores de Amé. rica (56). En la primera Korn figura entre pensadores españoles y la- 
tinoamericanos. En la segunda aparece junto a Horacio Mann, Sarmiento, José Pedro Varela, Gabino Barreda, Dewey y Vaz Ferreira, entre otros.

En el mismo período, es decir, aproximadamente entre 1939 y 1946 , también en la Argentina son intensos el recuerdo y el estudio de Korn. En I940 aparece el libro de Francisco Romero, Luis Aznar y Angel Vassallo, Alejandro Korn. Este volumen colectivo contiene: el trabajo de Romero que había figurado al frente de la edición de las Obras de Korn realizada por la Universidad de La Plata (III); unas "Apuntaciones biográficas" de Luis Aznar, que parcialmente reproducían las que habían precedido a la edición de Influencias filosóficas por la editorial Claridad, a las que ya nos hemos referido (I4); y un trabajo de Angel Vassallo titulado "Presentación de Alejandro Korn, filósofo" (I40). Vassallo define a Korn como "el primer idealista argentino", y encuentra en la meditación sobre la libertad el tema dominante de la filosofía de Korn. A despecho de las reticencias metafísicas del filósofo, no duda el crítico en atribuir a la libertad, tal como Korn la concibe, la significación de un absoluto metafísico. "Es lo absoluto en el hombre, y que sólo como personalidad puede darse. La libertad creadora sólo se quiere a sí misma, como absoluta creación. ... La libertad creadora de Korn es, en su sentido final, libertad metafísica" ( $\mathrm{r}_{4} \mathrm{O}$, p. 88). En un trabajo posterior ("La filosofía de Alejandro Korn", I945) (I4I), Vassallo ha reiterado esta interpretación. Vuelve a insistir aqui en que "el punto de partida del filosofar de Korn es, pues, la experiencia de la libertad" (I4I, p. 53). Al referirse nuevamente al idealismo de Korn, lo considera "original" y afirma: "Me he ocupado algunos años del idealismo y no conozco forma alguna de idealismo filosófico en que quepa exactamente la posición del doctor Korn" (15I, p. 53). Por último, señala la raigambre kantiana de la cautela metafísica de Korn. "El doctor Korn -escribe Vassallo-, como filósofo, tenía muchos de los rasgos que definen la mentalidad criticista: un agudo sentido crítico, es decir, una actitud refleja, vuelta lo más a menudo a los poderes, funciones y alcances del espíritu humano antes que a los objetos mismos que lo solicitan; el gusto del saber racional claro y preciso; la cautela y la pulcritud del pensamiento; el miedo de hacer el romántico" (14I, P. 56). En general, los artículos de Vassallo se cuentan entre los que han penetrado más a fondo en la trama de la construcción filosófica de Korn.

La Universidad Popular Alejandìo Korn, de La Plata, publicó, en varias oportunidades, estudios y recuerdos sobre el maestro. Segundo 
A. Tri, Gabriel del Mazo, Luis Reissig y José Luis Romero suscribieron un pequeño volumen titulado Alejandro Korn. Tri se ocupó de la "Significación de Alejandro Korn" (I38); del Mazo de la actuación de Korn durante la Reforma Universitaria (3r); Reissig evocó aspectos de la persona del maestro, especialmente de la época en que se fundó el Colegio Libre de Estudios Superiores (9r); José Luis Romero, finalmente, destacó el papel desempeñado por la experiencia y el saber históricos en la obra de Korn (124).

Otro pequeño volumen con el mismo título fue publicado en I942. Colaboraron en él Ana María R. de Aznar, Angel Poncio Ferran ło y María de Villarino. La primera contribuyó con una breve, sentida y bien escrita semblanza del maestro, titulada "Cuando nuevas voces pregunten" (II). Poncio Ferrando, con su artículo "Mi amigo el Director" (85), iluminó un aspecto de la biografía de Korn sobre el que nada se había escrito: su paso por el Hospital de Alienados de Melchor Romero. El autor, que había sido practicante en dicho hospital cuando Korn era director, nos revela, a través de anécdotas narradas en estilo llano, interesantes facetas de la personalidad del maestro. También la contribución de María de Villarino era de carácter biográfico: se refiere especialmente al ámbito de la influencia de Korn como profesor, maestro y jefe de grupo, sobre todo en La Plata (I44).

A la labor desarrollada por la Universidad Popular Alejandro Korn deben asociarse otros ensayos de autores vinculados estrechamente a ella. Entre esos ensayos deben recordarse: "Alejandro Korn, argentino ejemplar", de Arnaldo Orfila Reynal (77), que reproduce una conferencia pronunciada en 1942 en la Filial Bahía Blanca del Colegio Libre de Estudios Superiores; "Alejandro Korn, un filósofo de la libertad", de Alfredo Galletti, aparecido en Cuadernos Americanos, en 1946 (4I); "Alejandro Korn" y "La ciudad de don Alejandro", del mismo autor, publicados en 1955 en Sagitario, de Buenos Aires (42), y El Argentino, de La Plata (43), respectivamente; "Alejandro Korn", de Juan Manuel Villareal, aparecido en La Nación, de Buenos Aires, en 1957 (I43).

En 1946 , con motivo de cumplirse los primeros diez años de la muerte de Korn, la revista Cursos y Conferencias le dedicó un homenaje. Unas palabras de Francisco Romero preceden al trabajo más extenso, "Alejandro Korn y el pensamiento contemporáneo", de Raúl Alberto Piérola, que muestra las relaciones del pensamiento de Korn con otros filósofos contemporáneos, y que años más tarde fue publicado en inglés en Pbilosopby and Phenomenological Research (84). Siguen a éste otros 
trabajos más breves: "Los Apuntes filosóficos de Korn", de Norberto Rodriguez Bustamante (ror); "Alejandro Korn, maestro", de Juan Carlos Ghiano (46); "Korn, filósofo de la libertad", de Jorge Galíndez (40); e "Ideas pedagógicas de Alejandro Korn", de Angel D. Márquez (74).

Francisco Romero, infatigable en el recuerdo y el estudio del maestro, publicó en 1942 un artículo titulado "Tiempo y destiempo de Alejandro Korn" (II4). En él se proponía examinar "el tema del papel de Alejandro Korn en nuestra filosofía", es decir, en el pensamiento argentino e hispanoamericano. Para Romero, Korn "inicia entre nosotros lo que podria denominarse la vida filosófica, no sólo en el sentido de la entera consagración, ... sino sobre todo como entrega plena a una vocación elevada a dignidad de destino, reforzada por un cúmulo de aptitudes extrañas en cualquier parte y que resultan sorprendentes si se considera su espontaneidad, su afirmación y robustecimiento progresivos y la callada energía con que debieron afirmarse contra la inclemencia del contorno" (II4, pp. 239-40). "En cuanto a su legado filosófico - continúa Romero- lo que en él más importa es su enérgica convicción - tan pensada como vivida - de que el hombre es ante todo un impetu hacia adelante y hacia arriba, un ser que se hace a sí mismo triunfando sobre la fatalidad natural: el espíritu como progresiva libertad y autonomía, la libertad como continua creación" (II4, p. 24r).

Para terminar con el análisis de la producción argentina de este período nos quedan dos trabajos de interés: "Las dos evidencias de Alejandro Korn" (6), de Enrique Anderson Imbert, y "Cinco sonetos religiosos de Alejandro Korn", de Vicente Fatone (35). Breve pero sugestivo, el ensayo de Anderson Imbert se basa en la afirmación de que Korn partió de dos evidencias: "la primera, que no podemos conocer sino lo que englobamos en nuestra conciencia; la segunda, que la realidad que conocemos en nuestra conciencia no es toda la realidad" ( 6, p. 34). Según Anderson, Korn no habría puesto el mismo énfasis en ambas: la primera la habría predicado en voz alta; la segunda, con una sordina de dudas y reservas. "Este altibajo de la voz - reza la imagen de Anderson Imbert- echó a perder la unidad de la melodía" (6, p. 34). La tesis principal de nuestro crítico es que algunos aspectos de la filosofía de Korn - por ejemplo, uno tan importante como la ética-suponen con toda intensidad la segunda evidencia, la que Korn habría expresado en voz baja. $Y$ esto sería, si no una inconsecuencia, por lo menos una falta de proporción. Además, Anderson Imbert coincide con Vassallo al atri- 
buir significación metafísica al concepto de libertad en Korn: "la libertad psicológica ... sería concomitante con la libertad metafísica. La personalidad autónoma se convierte así en una realidad absoluta" ( $6, \mathrm{p}$. 40).

En la revista Libertad Creadora publicó Vicente Fatone cinco sonetos 'de Korn, precedidos por el ensayo a que hicimos referencia. Si no todos, por lo menos los dos últimos sonetos disuenan a primera vista, por su tono religioso, con la obra en prosa - tendríamos que decir con la obra, a secas- de Korn, y plantean un difícil problema al intérprete de su filosofía. ¿Es contradictorio el contenido de estos sonetos íntimos con su filosofía tal como la conocemos por sus trabajos de intención teórica? ¿Son ellos secundarios o dan la clave de su pensamiento? ¿Es posible encontrar en sus escritos una unidad última a la cual reconducir la religiosidad de los sonetos y la filosofía de la libertad creadora? Estas preguntas no podrían soslayarse en una interpretación de conjunto del pensamiento de Korn. La respuesta de Fatone se decide abiertamente por uno de los dos términos que originan el problema. En efecto, nuestro crítico cree que en los sonetos está el sentido verdadero de toda la obra de Korn, la clave para entenderla. "Es fácil descubrir en los sonetos -escribió Fatone- una progresiva confesión religiosa que culmina en Dolor [el último de los sonetos mencionados] y que por parecer contradictoria con el pensamiento expuesto en la cátedra y en el libro necesita ser justificada" (35, p. 253). "Alejandro Korn creía - continúa nuestro autor-que en la unión mística se da la libertad absoluta; y que en ella se da también, por 'paradoja inevitable, el aniquilamiento personal'. ... En su Carta a Alberto Rougès, Alejandro Korn dijo esto otro: 'Me permito el equívoca de confundir los verbos creer y crear'. ¿No podríamos nosotros, ahora, permitirnos el equívoco de confundir libertad creadora y libertad creyente? Insistiendo en el equívoco ditiamos que el único tema del pensamiento de Alejandro Korn fue este: Creo, Señor, creo libremente" (35, pp. 254-55).

Se comparta o no la tesis de Fatone -y el autor de estas líneas tiene muchas reservas sobre ella- no puede desconocerse su mérito al poner de relieve el problema. Como toda tesis extrema, la de Fatone tiene una parte de verdad que pasa a incorporarse al planteo del problema. 
4. LA bibliografía Más RECiente Y LA RECORdACIÓN DEL CENTENARIO

Como hemos visto, a diez años de su fallecimiento Korn era ampliamente conocido y recordado en Argentina y América en general. Los trabajos anteriores contribuyeron a fijar las lineas fundamentales de su perfil y a concederle su lugar en la historia de la cultura latinoamericana. Ya como valor así consagrado, continuaron el estudio de su obra y los escritos de recordación y homenaje.

Uno de los estudiosos que más han en riquecido recientemente la bibliografía sobre Korn es, sin duda alguna, Hugo Rodríguez Alcalá. En perseverante labor, Rodríguez-Alcalá ha estudiado aspectos de la biografía, la personalidad y el pensamiento de Korn. En lo que respecta a lo biográfico y personal, a veces ha obtenido datos nuevos y of recido cuadros biográficos minuciosos, como en "Apuntes para una biografía de Alejandro Korn" ( $(96)$, y otras ha dado nueva vida a crónicas y recuerdos, como en "Evocación de Alejandro Korn en Melchor Romero" (97), donde nos pinta el ambiente del hopital provinciano donde Korn actuó largos años como director. En "El socratismo de Alejandro Korn" (roo), en cambio, son los valores del maestro los que son puestos de relieve.

Sus ensayos de mayor hondura crítica son los titulados "Alejandro Korn y el concepto de la historia" (99) y "Razón y sentimiento en Alejandro Korn" (98). En el primeto trató de mostrar "cómo, pese a que Korn afirma la inevitable relatividad del conocimiento histórico, la historia, según doctrina implícita del filósofo, nos revela una verdad fundamental e incondicionada que trasciende la susodicha relatividad" (99, p. 5 I). En efecto, junto a ciertas consideraciones sobre la historia, como saber o ciencia, se encuentran, en Korn otras que, si no constituyen una filosofía de la historia, por lo menos pueden considerarse su núcleo o idea fundamental. Estas últimas no son sino un corolario de sus ideas sobre la "libertad creadora". En el segundo de los trabajos mencionados, Rodríguez-Alcalá ha replanteado el problema del fondo religioso del pensamiento de Korn, problema al que ya atendimos cuando examinamos los términos en que fue puesto por Vicente Fatone. Rodríguez-Alcalá expone los conceptos de religión y metafísica en Korn, concluyendo que ellos no hacen pensar en una concepción religiosa en su pensamiento. Luego examina los sonetos publicados por Fatone, tratando de cesentrañar su sentido y relacionándolos con el resto de la obra. Del 
último soneto afirma que revela un "fervoroso cristianismo inequívoco" (98, p. 27). En los últimos versos de este soneto, escribe RodríguezAlcalá, "al tevés que en su prosa, nos deja el testimonio de que había hallado una solución satisfactoria, positiva, inequívoca, exaltadora, al 'problema sentimental'" (98, p. 28). Pese a esta conclusión, nuestro autor no extrae consecuencias tan extremas como Fatone. Su planteo es más equilibrado y consiste más bien en mostrar la coexistencia de ambos aspectos, como vertientes de un mismo pensamiento filosófico.

Recientemente la obra estrictamente filosófica de Korn ha sido objeto de un análisis muy particularizado por parte de un crítico norteamericano, William Kilgore, quien le ha dedicado una tesis titulada. Alejandro Korn's Interpretation of Creative Freedom (58). No podriamos seguir en detalle el trabajo de Kilgore y nos limitaremos a dar una idea de su contenido. Cada opinión filosófica de Korn es examinada minuciosamente por el autor y a la exposición sigue, en cada caso, el comentario y la crítica. Con este método se examinan la teoría del conocimiento, el concepto de metafísica, la teoría de los valores y la idea de libertad creadora. Este cuadro se completa con el análisis de las principales influencias que, según el crítico, han obrado sobre Korn, y con una comparación de las concepciones de la libertad en Korn, Kant y Bergson. Los dos últimos y Dilthey son los tres filósofos curopeos a quienes Kilgore atribuye mayor influencia sobre Korn. Señala asimismo la deuda de Korn con Alberdi. Kilgore ha destacado también la profundidad y agudeza de Korn en la visión de la historia de la filosofía.

Kilgore define la posición gnoseológica de Korn, a la que supone muy influenciada por Dilthey, como un "fenomenalismo epistemológico en el cual el conocimiento está limitado a los hechos de la conciencia" ( 58, p. 58). Esta posición, a la que nuestro crítico califica de solipsista, sería, en su opinión, la responsable del escepticismo de Korn sobre la posibilidad de la metafísica. Este escepticismo, sin embargo, no habría impedido que Korn hiciera metafísica y que algunas de las características por las cuales define al sujeto frente a la realidad objctiva coincidan con las aceptadas tradicionalmente por el idealismo voluntarista. Kilgore se extiende largamente sobre la axiología y la ética de Korn destacando, entre otras cosas, que la teoría de los valores del filósofo argentino, por su carácter esencialmente descriptivo, no es adecuada para solucionar satisfactoriamente el problema de la obligación moral. El relativismo axiológico es también objeto de crítica por parte de Kilgore. Por último, una de las objeciones más frecuentes en este trabajo es la que se refiere 
a la falta de adecuado desarrollo de muchas cuestiones: el crítico señala opiniones que habrían exigido mayor fundamentación, problemas que no quedan totalmente aclarados, zonas de la teoría que, pese a su importancia dentro de ésta, no reciben el tratamiento que fuera necesario. Repetimos que lo dicho sólo da una idea general de un trabajo muy rico en detalles, cuyo cabal resumen y discusión no cabría en este artículo panorámico.

Considerado como exposición y crítica de las ideas filosóficas de Korn, y con independencia de las naturales discrepancias que cada lector podría señalar entrando en detalles, el de Kilgore es uno de los trabajos más detallados que se conocen. Queremos observar, sin embargo, como una cuestión de método para la cual la obra de Kilgore nos presta la ocasión, que la restricción del examen a lo estrictamente filosófico limita la posibilidad de una comprensión histórica total de Korn, sin la cual su obra no puede ser cabalmente entendida. Por tal comprensión entendemos una interpretación que junto al análisis de la obra filosófica como conjunto de proposiciones teóricas, atienda a la singulacidad de la persona del filósofo, a la de su ambiente y su momento histórico; ausculte la significación de esas puras ideas para la tradición y la historia cultural en que se insertan; y examine el modo en que esa tradición y esa historia pudieron influir a su vez en aquellas ideas. La falta de esa interpretación geneta un doble peligro: por un lado, olvidar que ciertas notas del pensamiento filosófico pueden estar determinadas por un contexto más amplio -biográfico, moral, ideológico en un sentido general, histórico, etc.- que el puramente teórico; por otro lado, no advertir que algunas críticas, ajustadas cuando se tratan de lo filosófico en sentido estricto, no se aplican a la comprensión total del pensador. Atendamos, para dar un ejemplo y dejar ya el plano de las generalidades, al hecho señalado con toda justicia por Kilgore, de que en Korn muchas ideas están presentadas en forma esquemática y sin el debido desarrollo. Desde el punto de vista estrictamente teórico esto es una deficiencia, y el crítico no debe dejar de señalarla. Pero esta deficiencia no tiene la misma significación histórica en un filósofo que se asienta en una larga y madura tradición, y habla despreocupadamente a sus iguales, que en un pensador que apenas está pugnando por crear, casi desde la nada, las condiciones de un clima filosófico. Korn tenía-creo-la rara virtud de elaborar su pensamiento en sintonía con las posibilidades de su ambiente. Así, parte de sus pontecialidades se volcaron en su propia meditación, y parte en la creación de un clima filosófico en un medio que 
carecía de él. Creo que pensaba que la elaboración de un sistema filosófico perfectamente delineado era menos urgente que crear las bases de lo que luego Romero llamaría la "normalidad filosófica". Esta circunstancia contribuyó - sin ser la única- a determinar el modo de expresión y de comunicación de Korn. La crítica que tomamos como ejemplo es, pues, perfectamente válida en el campo teórico, pero imperfecta en el terreno de la comprensión histórica total del pensador. $Y$ sólo cuando se aclara lo segundo, queda lo primero enunciado con plenitud de sentido.

Por supuesto, no siempre las opiniones sobre Korn han sido elogiosas. No queremos decir que los artículos a que nos hemos referido hasta ahora no contengan críticas, objeciones o reservas. Las contienen, pero podríamos afirmar que se da en ellos una simpatía básica sobre la que se erigen las diferencias. La plataforma de estimación de otros, muy escasos en número en comparación con los anteriores, es distinta: están informados por una cierta indiferencia, cuando no por un violento rechazo. Apreciaciones de este tipo son corrientes en la crítica que recoge todo pensador. Saber de dónde vienen, qué aspecto de la obta las provoca, cuál es su tenor, son factores que contribuyen a perfilar el cuadro de la reacción que el autor y su obra han provocado. $Y$ aun podría decirse, en algunos casos, que las discrepancias pueden ser más ilustrativas que las coincidencias, a los efectos de situar al autor.

Con el título paradójico de "En defensa de Korn" (I8), el padre Roberto Brie publicó en la revista Estudios, de Buenos Aires, un artículo enderezado a criticar acerbamente el capítulo que Korn dedicó a la influencia de la escolástica en la época colonial, en su obra Influencias filosóficas en la evolución nacional. Después de poner aparte respetuosamente la intención de Korn, porque "de lo interno la Iglesia no juzga" (I8, p. I30), Brie concluye, del análisis del capítulo mencionado, que Korn no fue filósofo ni historiador. El tono de su crítica es violento. Algunas afirmaciones resultan intolerables para el buen conocedor de Korn. Así, cuando dice que Korn "castigó severa y ciegamente" al "pensamiento cristiano" (I8, p. I30). (Bastaría, para convencerse de lo contrario, leer lo que Korn escribió sobre San Agustín, Pascal y el propio Santo Tomás). Otras son risueñas: Korn no habría leído "más que manuales de filosofía decadente redactados a mediados del siglo pasado y nutridos por los repetitorios de los historiadores protestantes del siglo XVI y XvII" (I8, p. I32). Allí habría bebido Korn el "prejuicio protestante", cuya presencia en su pensamiento seria visible cuando habla 
"de la posición retrógrada y cerrada en que permaneció España, como consecuencia de su oposición a la entrada de las nuevas posiciones protestantes del libre examen" (18, p. 133). Otras afirmaciones tienen por intención refutar lo dicho por Korn sobre la escolástica o su influencia ideológica en la época colonial. Las observaciones de tipo histórico no abundan, sin embargo, $y$ el artículo de Brie no podría considerarse un examen sistemático o una refutación orgánica realizada desde un punto de vista estrictamente histórico. En un caso, Brie hace decir a Korn sobre Suárez lo que aquél no dice del filósofo español, sino del espíritu con que España organizó y administró las colonias. ${ }^{6}$

No se trata, por supuesto, de discutir aquí los detalles de la interpretación histórica de Korn, la cual, como toda interpretación histórica, está sujeta a revisión. Sin embargo, aunque nos importaba solamente reflejar la actitud que informaba la crítica y dar una idea del contenido de ella, podríamos reprochar al crítico que no haya llevado su atención hacia el libro bajo análisis - Influencias filosóficas en la evolución nacional-tomado en su conjunto y considerado dentro de la escasa bibliografía sobre el tema. A esta luz habría encontrado valores que necesariamente tenían que escapársele desde la posición adoptada.

Conviene destacar que no siempre la crítica proveniente del campo católico tuvo esas características. Tomás D. Casares, profesor de Filosofía en la Universidad de Buenos Aires y uno de los principales representantes del neotomismo en la Argentina, escribió en I930: "Porque con el doctor Korn .... es posible, muy posible disentir; pero hasta en la

6 Es fácil mostrarlo con los textos. Dice Korn: "Semejante reacción escolástica y autoritaria prevalecía cuando, terminada la conquista, España hubo de organizar, administrar y explotar sus colonias. Desde luego, se columbra qué espiritu babia de presidir a esta obra, en que se refleja la alianza del dogmatismo y del absolutismo: un espiritu de benevolencia paternal, religioso ante todo, pero doctrinario y casuista, de intolerancia dogmática, de molesta tutela para los subordinados, ajeno a los intereses reales de la colectividad, opuesto a toda acción o iniciativa autonómica, sin otro anhelo que la sumisión de las gentes a la autoridad, a la costumbre y a la rutina..." (pág. 47 de las Obras completas, edición Claridad). El subrayado es nuestro, y lo utilizamos para destacar que lo dicho en la parte final del pasaje se refiere al espíritu con que España realizó la colonización, en opinión de Korn. Pero dice Brie: "Concede [Korn] a Suárez "una inteligencia 'robusta y original', pero le achaca sin restricción alguna 'su criterio medieval'. ¿Cuál era su pecado [el de Suárez] ? Pues 'el dogmatismo y el absolutisno; un espiritu de benevolencia paternal, religioso ante todo pero doctrinario y casuista, de intolerancia dogmática, de molesta tutela para los subotdinados, ajeno a los intereses de la colectividad, opuesto a toda acción o iniciativa autónoma, sin otro anhelo que la sumisión de las gentes a la autoridad, a la costumbre y a la rutina' " (18, p. 131). Y trata de mostrar Brie, eligiendo uno de los supuestos reproches dirigidos por Korn a Suárez, que éste tuvo real espíritu de iniciativa. Demostración inútil, porque Korn se refería al tegimen colonizador español y no al ilustre fílósofo de la Contrarreforma. 
oportunidad de los más hondos disentimientos, se levanta, como apoyándose en ellos, el reconocimento de que estamos en presencia de egregias calidades espirituales. En todas las actitudes del doctor Korn, hasta en sus impetus apasionados, hay un inconfundible timbre de nobleza. Es por eso que el doctor Korn ha podido ser maestro de todos, hasta de quienes están muy lejos de sus convicciones intelectuales, o disienten con él en la apreciación de lo concreto circundante. El que habla, por ejemplo, conserva con cariño el original de ciertas tesis que la bondad del doctor Korn anotó minuciosamente superando las divergencias ideológicas con un admirable esfuerzo de comprensión: esfuerzo demostrativo no por cierto de fría objetividad, sino de cautivante generosidad espiritual; una generosidad que explica el vivo respeto teñido de afecto que nos inspira siempre el doctor Korn" (139, p. 302 ).

Hay también unas páginas de Coriolano Alberini que deben contarse entre las críticas adversas. Esas páginas pertenecen a un discurso escrito para la inauguración del Primer Congreso Nacional (que fue, en realidad, internacional) de Filosofía, realizado en Mendoza, Argentina, en I949 (ז). En dicho discurso traza Albertini una sumaria historia de la vida filosófica argentina en los últimos cincuenta años, aproximadamente, de la cual ahora sólo nos interesa la referencia a Korn. ¿Qué imagen presenta del filósofo de la libertad creadora quien fue su compañero de muchos años en el movimiento de renovación antipositivista que tuvo su escenario principal en la Facultad de Filosofía y Letras de Buenos Aires?

Korn aparece como un profesor entre otros, con algunas buenas cualidades espirituales, tales como haber sido "maestro de espíritu distinguido y excelente colega de profesores y estudiantes" ( $I$, p. 79). Esta es la nota más alta en el elogio. Por lo demás, sus progresos habrían dependido de la renovación iniciada por los "jóvenes". (Por menos que se quiera caer en suspicacias de mal gusto, no hay más remedio que suponer, según el contexto, que entre los "jóvenes" estaba Coricilano Alberini). Los jóvenes parece que también le enseñaron filosofía: "cultivó intesamente la intimidad cordial con jóvenes filósofos, a quienes no paco debió en su formación filosófica" (I, p. 70). Esto no debiera extrañarnos, dado que, según Alberini, "Korn era fundamentalmente una naturaleza literaria" y las conclusiones finales de su filosofía saben a bella retórica" (I, p. 70). En cuanto a su posición filosófica, he aquí cómo la resume Alberini, con evidente superficialidad: Korn opuso al realismo ingenuo un "idealismo ingenuo". "Después coronó 
este 'idealismo ingenuo' con una categórica filosofía de la acción, apenas esbozada. Como su gran maestro, Schopenhauer, hipertrofia la voluntad humana a costa de la razón. El ser humano se presenta aquí como un gigante microcéfalo. Su vida psíquica se reduce a gritar la palabra 'libertad'. Preconiza una 'libertad creadora' esencialmente irracional. El alarido es lanzado por el gigante para animarse en medio de la obscuridad del irracionalismo. Por eso, Korn salta del 'idealismo ingenuo', de fondo búdico, a una indeterminada filosofía de la acción" (I, pp. 69-70).

Junto a errores de hecho y de interpretación, hay en las páginas de Alberini una evidente - $y$, para nosotros, reprochable-intención de desmerecimiento, que se agrava porque Alberini habia sido testigo cercano de la vida filosófica de Korn, y porque las mencionadas páginas estaban destinadas a ser leídas ante un auditorio donde había profesores y estudiosos extranjeros que, no enterados de ciertos entretelones domésticos, creerían de buena fe lo que se les decía por intermedio de un destacado representante del pensamiento filosófico en la Argentina. Una vez Alberini se autotituló "el patriarca cronológico de la filosofía argentina". ¿Nos dará esta autovaloración la clave para comprender su actitud hacia Korn?

La extensión que ha tomado este artículo nos obliga a limitarnos casi a la mera mención de otros trabajos recientes sobre Korn. Recordaremos, entre otros, nuevos trabajos de Eugenio Pucciarelli ("La filosofía de Alejandro Korn", I954, (87); "La lección de Alejandro Korn", I959 (88); y "Alejandro Korn y el pensamiento europeo", I960 (89); y de Francisco Romero Alejondro Kom, filósofo de la libertad (reunión de artículos, I956) (120); "Alejandro Korn en la vida y en la muerte", I955 (I.I9); "Sentido de la imposición del nombre de Alejandro Korn al Instituto de Filosofia", I959 (I2I); y "Personalidad y pensamiento de Alejandro Korn", I960 (122)). A ellos hay que agregar: el folleto "Alejandro Korn, mi padre", de Inés Korn (6I); dos artículos del pensador mexicano Francisco Larroyo ("Deústua, Korn, Molina y Vaz Ferreira, en paralelo" (63) y "El centenario de Alejandro Korn, gran filósofo de nuestra América" (64)); otros dos de William Kilgore ("Latin American Philosophy and the Place of Alejandro Korn" (60) y "Alejandro Korn y la teoría relativista de los valores" (59)); un ensayo de León Dujovne en La Nación, de Buenos Aires ("Alejandro Korn" (33) ) y otro de Luis Adolfo Dozo en El Día, de La Plata ("Alejandro Korn y el filosofar argentino (32)); sendos folletos de Norberto Rodriguez Bustamante (Alejandro Korn y el problema de la 
cultira nacional (IO2)) y de Eduardo Pettoruti (Centenario del nacimiento de Alejandro Korn. Síntesis cronológica de su vida y su obra (82) ); finalmente, el artículo del escritor español Julián Izquierdo Ortega, "Metafísica y ética en el pensamiento de Alejandro Korn" (55), el estudio preliminar de Gregorio Weinberg a una reedición de Influencias filosóficas $\left(\mathrm{I}_{4} 8\right)$ y el del autor de estas páginas a otra reedición de artículos de Korn ("Los ensayos de Alejandro Korn sobre la historia de la filosofí" ( 136$)$ ).

Algunos de estos trabajos se han escrito con motivo de celebrarse el centenario del nacimiento del filósofo (I860-1960). Con este motivo, su memoria ha sido recordada en numerosos actos, tanto en su país como en el extranjero. En la Argentina se constituyó la "Comisión Americana de Homenaje al doctor Alejandro Korn", la cual promovió actos, conferencias y publicaciones, dando gran relieve y amplio escenario a la recordación. Como homenaje del centenario, la Universidad de La Plata prepara un volumen especial sobre Korn, con colaboraciones de toda América. La Revista de la Universidad de La Plata, por su parte, ha publicado varios artículos sobre el pensador argentino, en dos números de 1960 ( Ir y r2), que se caracterizan por enfocar distintos aspectos de la obra de Korn. Así, Rubén Córsico ha escrito un trabajo muy valioso sobre "La actividad psiquiátrica de Alejandro Korn" (27), iluminando un aspecto muy poco estudiado, con datos muy importantes para conocer la primera etapa del desarrollo ideológico de Korn; Ricardo Maliandi se refirió al relativismo axiológico de Korn ("Límites y aportes del relativismo axiológico de Alejandro Korn" (69) ), en el que muestra que dicho relativismo está limitado por el catácter absoluto que concede a la libertad y que, no obstante, dentro de él se dan aportaciones positivas a la téoría de los valores; Juan Mantovani ("Alejandro Korn. Bases para una filosofía de la educación" (72)) ha destacado los elementos que en la filosofía de Korn permiten fundamentar un "personalismo pedagógico"; Luis Aznar, en "Alejandro Korn y la Universidad argentina" (15), ha dado el mejor trabajo que se conoce sobre el asunto; finalmente, el artículo de Eugenio Pucciarelli, "Alejandro Korn y el pensamiento europeo" (89), es una valiosa aportación, no sólo por situar a Korn en las coordenadas del pensamiento occidental, sino porque, a la vez que el autor realiza esa labor, va afinando, de paso, una aguda interpretación del pensamiento del filósofo, de la cual el intérprete de aquél puede sacar gran provecho. Esta serie de artículos se complementa con dos testimonios, uno de José Rodríguez Cometa (IO4) 
y otro de Delfina V. D. Ghioldi (50). Por último, y en la imposibilidad de hacer mención detallada de todos los trabajos recientes, nos referiremos a los ya citados de Norberto Rodríguez Bustamante (ro2) y Gregorio Weinberg ( $x_{4} 8$ ). Ambos trabajos tienen en común dos características: centran el aspecto expositivo y crítico en el examen de $I n$ fluencias filosóficas en la evolución nacional, y remiten los planteos de Korn a la situación argentina actual, probando, a través de la viva preocupación nacional de sus autores, la fecundidad de la meditación de Korn sobre la realidad ideológica y espiritual de su país.

\section{Conclusiones}

Hemos recorrido el proceso de la difusión de Korn a través de la crítica que inspiró su obra y hemos visto cómo su figura se agranda después de su muerte. Después de haber registrado más de cien títulos consagrados a él, sin contar entre ellos los artículos o libros que al tratar de la filosofia latinoamericana o argentina lo mencionan, exponen o interpretan, no podemos decir que Korn es un desconocido. Puede decirse, por el contrario, que Korn ha originado una abundante bibliografía. Quizá lo más interesante sea su difusión fuera de Argentina. Del centenar de títulos aludidos, la cuarta parte corresponde a autores no argentinos. Si se agregan los trabajos generales excluidos en aquel número y los artículos publicados por autores argentinos en revistas extranjeras, se tendrá una idea de la difusión de Korn fuera de su país. Tenemos la sospecha de que ninguno de los pensadores latinoamericanos que jugaron, en otros países, un papel semejante al que Korn jugó en el desarrollo del pensamiento filosófico de la Argentina - Vaz Ferreira en Uruguay, Molina en Chile, Deústua en Perú, Caso y Vasconcelos en México, Varona en Cuba, etc.- ha tenido una repercusión semejante fuera de su país, sin que la comprobación de este hecho pretenda ser un juicio de valor.

En la difusión de Korn ha influido, sin duda, la impronta que dejó su personalidad de excepción en sus amigos y discípulos directos e, indirectamente a través de éstos, en aquellos que no llegaron a conocerlo. En la bibliografía sobre Korn hay mucho de recuerdo del hombre, de admiración por la persona, de homenaje al maestro. En relación con esto hay que afirmar que en todo análisis de la bibliografía sobre Korn merece lugar aparte la labor incesante de Francisco Romero: mucho del reconocimiento póstumo de Korn se debe a su acción y su testimonio, 
que se han concretado no sólo en sus autorizados trabajos, sino también en una prédica que ha inspirado estudios sobre Korn, en la Argentina y en el extranjero. También debe destacarse la difusión realizada por la Universidad Popular Alejandro Korn, de La Plata, fundada precisamen. te para mantener viva la memoria del maestro.

Después de examinada la bibliografía, ¿qué podemos concluir sobre el avance logrado en el conocimiento de Korn? ¿Hasta dónde y en qué aspectos es bien conocido?

No poseemos, ante todo, una biografía completa de Korn, en la que la vida y la obra del pensador se enmarquen en su contorno y en la época que le tocó vivir; pero hay muchos materiales adelantados para esa labor en varios trabajos de Luis Aznar y Hugo Rodríguez Alcalá, además de los esquemas biográficos trazados por Eduardo Pettoruti. Más abundantes todavía son otros ensayos - de indudable valor para una futura biografía- que contienen semblanzas del maestro, anécdotas y recuerdos. Estos, en su mayoría, provienen de amigos y discípulos que en La Plata o en Buenos Aires eran asiduos de su tertulia o de su mesa. Francisco Romero, Luis Aznar, Eugenio Pucciarelli, A. Orfila Reynal, Angel Poncio Ferrando, Ana María de Aznar, Juan Manuel Villareal, A. Sánchez Reulet, A. Galleti, A. Isusi, Segundo A. TriMaría de Villarino, son algunos de los que pueden contarse en ese grupo y de quienes hemos registrado artículos.

Son también abundantes los trabajos que se ocupan en general de la filosofía de Korn, sea porque den una idea global de su pensamiento, sea porque lo caractericen en sus principales rasgos. El trabajo de Romero que precede a las Obras editadas por la Universidad de La Plata (III); "Alejandro Korn, maestro de saber y de virtud", de Pucciarelli (86); "Las dos evidencias de Alejandro Korn", de Anderson Imbert (6); los dos artículos de Vassallo que mencionamos (I40-I4I) y la tesis de W. Kilgore $(58)$ se cuentan entre los intentos más logrados de caracterizaciones e interpretaciones generales. También hay trabajos sobre temas especialmente caros a Korn, como la acción (Anderson Imbert, (5)) la metafísica y la ética (Izquierdo, (55)), la libertad (Galletti, (4I) ), los valores (Kilgore (59) y Maliandi (69) ) y, por último, la historia (J. L. Romero (124) y Rodríguez Alcalá (99)).

Aspectos muy conexos con su pensamiento filosófico, y que asimismo han sido atendidos por sus críticos, son sus relaciones con el pensamiento europeo - asunto que puede considerarse bien estudiado en tres trabajos de Romero (IIO), Pucciarelli (89) y Piérola (84), respecti- 
vamente- y su apreciación de la historia filosófica (Pucciarelli (89) y Torchia Estrada (136)).

De los otros aspectos de la obra escrita de Korn, dos han sido bien atendidos: uno es su pensamiento pedagógico y sus ideas sobre la Reforma universitaria y la universidad en general, sobre el cual pueden senalarse por lo menos cinco títulos ( 3 I, 56, 72, 74 y i 5), destacándose el último, de Luis Aznar; el otro lo componen sus poesías. Sobre el volumen de poesías publicado por el Instituto de Estudios Germánicos de la Universidad de Buenos Aires hay un excelente trabajo de W. Mann (7I); sobre los llamados sonetos "religiosos" han escrito sendos artículos Fatone (35) y Rodríguez-Alcalá (98). A pesar de la calidad de estos dos trabajos, el problema planteado a la interpretación de Korn por el contenido de estos sonetos presenta todavía, a nuestro entender, algunas dificultades. Otros aspectos, en cambio, como sus escritos sobre la realidad argentina y sus opiniones sobre el socialismo, sólo recientemente han sido examinados con amplitud. ${ }^{7}$

Finalmente, una de las principales conclusiones a que nos lleva el presente examen es la falta de una obra orgánica que examine la vida y la obra de Korn en toda su amplitud y con todo detalle, aprovechando Ia bibliografía anterior, que como hemos visto es abundante y abarca casi todos los campos de la acción intelectual de Korn. La obra, en fin, que Alejandro Korn merece como hombre, como maestro y como pensador.

\section{Juan Carlos Torchia-Estrada}

Unión Panamericana,

Wasbington, D. C.

7 Para el primero de los dos aspectos mencionados véanse los números 50 , 102 y 148 de la bibliografia. En lo que respecta al "socialismo ético", remitimos a nuestro artículo "El socialismo ético de Álejandro Korn", que aparecerá en el volumen colectivo de homenaje que la Universidad de La Plata tiene en prensa. 


\section{BIBLIOGRAFIA*}

I. Alberini, Coriolano. "Discurso del Vice-Presidente del Comité de Honor y Secretario Técnico del Congreso, Dr. Coriolano Alberini, de la Universidad de Buenos Aires, en representación de los miembros argentinos". Actas del Primer Congreso Nacional de Filosofía, Tomo I. Mendoza, Universidad Nacional de Cuyo, I949, pp. 62-80.

2. - "Génesis y evolución del pensamiento filosófico argentino". Cuadernos de Filosofía, Buenos Aires, fascículo VII, núms. IоII-x 2, I952-I953, pp. 7-I8. [Reproducido en el libro de Luis Farré, Cincuenta años de filosofía argentina (véase núm. 34 de esta Bibliografía)].

3. Anderson Imbert, Enrique. "Prólogo" a Ensayos críticos, de Alejandro Korn. Buenos Aires, Claridad, r937, pp. 5-8.

4. —, "Alejandro Korn". Velrbum, Buenos Aires, núm. 86, I937, pp. 55-6r.

5. - "La acción en Alejandro Korn". La Nación, Buenos Aires, 26 de marzo de 1937.

6. - "Las dos evidencias de Alejandro Korn". En: Ensayos, Tucumán, I946, pp. 34-40.

7. Anónimo. "Ha muerto Alejandro Korn". La Vanguardia, Buenos Aires, 9 de octubre de 1936 .

8. —-, "Alejandro Korn". Nosotros, $2^{4}$ época, año I, núm. 7, octubre $1936, \mathrm{pp} .238-240$.

9. - - "Alejandro Korn, filósofo. 1936 - 9 de octubre - x937". Claridad, Buenos Aires, año XVI, núm. 318, octubre 1937. [Reproducido del número in del Correo de la Oficina de Cooperación Intelectual de la Unión Panamericana].

Io. - "Ejemplo de maestros". La Vanguardica, 27 de marzo de I938.

* Me complace testimoniar aquí mi agradecimiento a los siguientes amigos, que de un modo u otro me ayudaron en mis búsquedas bibliográficas: Inés Korn, Delfina Varela Dominguez de Ghioldi, Eugenio Pucciarelli, Enrique Anderson Imbert, Juan Manuel Villareal, Roberto F. Giusti, Eduardo Pettoruti y Norberto Rodríguez Bustamante. 
ri. Aznar, Ana María R. de., "Cuando nuevas voces pregunten". En: Ana Maria R. de Aznar, Angel Poncio Fernando y María de Villarino, Alejandro Korn. Tres testimonios. La Plata, Publicaciones de la Universidad Popular Alejandro Korn, 1942, pp. I720.

I2. AzNAr, Luis. "Alejandro Korn". En: Alejandro Korn, Influencias filosóficas en la evolución nacional. Buenos Aires, Claridad, I937, Pp. 5-20.

I3. L. A. [Luis AzNAR], "Alejandro Korn". En' Alejandro KorN, Obras, tomo II; Filósofos y sistemas. Notas bibliográficas y cartas. La Plata, Universidad Nacional de La Plata, 1939, pp. 335-340.

I4. - "Apuntaciones biográficas". En: Francisco Romero, Angel Vassallo y Luis AzNar, Alejandro Kom. Buenos Aires, Losada, I940, PP. 93-II3.

15. —- "Alejandro Korn y la universidad argentina". Revista de la Universidad. Publicación de la Universidad Nacional de La Plata. La Plata, núm. 12, setiembre-diciembre 1960, pp. Ir-27.

r6. Bar Ja, César. "Alejandro Korn". Revista Iberoamericanta, México, vol. II, noviembre 1940 , Pp. 359-382. [Reproducido en Cursos y Conferencias, Buenos Aires, año XIII, núm. 155, Pp. 347-364].

I7. Bejarano, Manuel. "Para Alejandro Korn, constituyó la acción la esencia misma de su vida". El Día, La Plata, i9 de noviembre de I944.

I8. BriE, Roberto. "En defensa de Korn". Estudios, Buenos Aires, tomo 83, núm. 444, abril-junio I950, pp. I29-r38.

I9. Brightman, Edgar S. "Personalism in Latin America". The Person. alist, vol. XXIV, núm. 2, April, Spring 1943, pp. 147-162.

20. Carrillo Nárvaez, Alfredo. La trayectoria del pensamiento fi. losófico en Latinoamérica. Quito, Editorial Casa de la Cultura Ecuatoriana, (Ensayistas Ecuatorianos), r959, 334 p.

2r. Casanueva Díaz, H. "Alejandro Korn, filósofo y maestro". Cursos y Conferencias, Buenos Aires, Año VII, vol. XIII, núm. I-2, abril-mayo I938, pp. I93-I94.

22. CASAs, Manuel Gonzalo. Introducción a la filosofía. Tucumán, Instituto de Filosofía, Universidad Nacional de Tucumán (Serie Didáctica, 5) I954. 
23. Castillo, Fabián. "Alejandro Korn y la realidad social y política". La Vanguardia, Buenos Aires, 9 de actubre de I94r.

24. Castillo Arraez, Alberto. "Alejandro Korn, filósofo de la lucha redentora". Tierra Firme, Caracas, marzo-abril ro54.

25. Colle, Elio M. A. "Influencias filosóficas en la evolución nacional'. [Reseña bibliográfica] Claridad, Buenos Aires, año XV, núm. 310, febrero 1937.

26. Comisión americana de homenaje al Dr. Alejandro Korn. Sintesis cronológica de la vida y obra de Alejandro Korn. La Plata, I960. $6 \mathrm{p}$.

27. Corsico, Rubén. "Ia actividad psiquiátrica de Alejandro Korn". Revista de la Universidad. Publicación de la Universidad Nacional de La Plata. La Plata, núm. I I, mayo-agosto I960, pP. 77-88.

28. Coviello, Alfredo. "Una página de historia en la naciente filosofía argentina". La Gacela, Tucumán, I" de enero de I937. [Reproducido en Una página de bistoria en la naciente filosofía argentina y otros ensayos críticos. Tucumán, Grupo Septentrión, I942, pp. 46-55].

29. —- "El pensamiento filosófico y su expresión en la Argentina". En: La esencia de la contradtcción, Tucumán, Grupo Sententrión, I939, Pp. 57-I54.

30. CRAwFord, William Rex. A Century of Latin-American Tbought. Cambridge, Massachussets, Harvard University Press, I944, pp. I4 2 -I 48 .

3r. DeL MAZo, Gabriel. "Korn y la reforma universitaria". En: Segundo A. TRI, Gabriel del Mazo, Luis Reissig, José Luis RomeRo, Alejandro Korn, La Plata, Publicaciones de la Universidad Popular Alejandro Korn, I94I, PP. 25-39.

32. Dozo, Luis Adolfo. "Alejandro Korn y el filosofar argentino". El Dia, La Plata, I9 de noviembre de I960.

33. Du jovne, León. "Alejandro Korn". La Nación, Buenos Aires, 23 de junio de I960.

34. Farre, Luis. Cincuenta años de filosofía argentina. Buenos Aires, Peuser, I958, PP. IoI-I33. 
35. Fatone, Vicente. "Cinco sonetos religiosos de Alejandro Korn". Libertad Creadora, La Plata - Bs. As., tomo I, núm. 2, abril-mayojunio I943, pp. 253-258.

36. —- "La libertad en la historia del pensamiento argentino". Cursos y Conferencias, Buenos Aires, año XIV, vol. XXVIII, núm. I67, febrero I946, pp. 223-235.

37. Ferrrater Mora, José. "Alejandro Korn". En: Diccionario de Filosofía, Buenos Aires, Ed. Sudamericana, $4^{\mathrm{a}}$ ed., I958, pp. 77I772.

38. Finlayson, Clarence. "La filosofía en la Argentina". Universidad de Antioquía, Medellín, Colombia, núm. 70, mayo de 1945, Pp. 327-332 [Tomo XVIII, que abarca los número 69-70-71-72].

39. Franquiz, José A. "Alejandro Korn". En: The Dictionary of Pbilosopbby, edited by Dagobert D. Runes, New York, s. f., Philosophical Library, p. $x 6$.

40. Galindez, Jorge. "Korn, filósofo de la libertad". Cursos y Conferencias, Buenos Aires, año XV, vol. XXX, núm. 175-176, octubre-noviembre I946, pp. 3I-35.

4r. Gallettr, Alfredo. "Alejandro Korn, un filósofo de la libertad". Cuaderno Americanos, año V, núm. 6, noviembre-diciembre 1946, PP. I40-I 47 .

42. —- "Alejandro Korn". Sagitario, Buenos Aires, núm. I, I955, Pp. 79-82.

43. - - "La ciudad de don Alejandro". El Argentino, La Plata, I9 de noviembre de 1955 .

44. GaOs, José. Antologia del pensamiento de lengua española en la edad contemporánea. México, Editorial Séneca, 1945, LVI + I4I $\mathrm{I}$ P.

45. - "Un siglo de pensamiento latinoamericano". Cuadernos Americanos, México, año IV, vol. XX, marzo-abril I945, PP. II8-I30 [Sobre el libro de Crawford del mismo título (núm. 30 de esta Bibliografía)].

46. GHino, Juan Carlos. "Alejandro Korn, maestro". Cursos y Conferencias, Buenos Aires, año XV, vol. XXX, núm. 175-r76, octubre-noviembre I946, pP. 25-30. 
47. GHroldr, Delfina V. D. de. "Alejandro Korn: los Ensayos filosóficos". Nosotros, Buenos Aires, año XXIV, núm. 256, septiembre 1930, pp. 288-295.

48. - Alejandro Korn, szzs ensayos filosóficos. Biblioteca de Graduados de la Facultad de Filosofía y Letras. [Buenos Aires (?), s.f.]

49. - "Las ideas de progreso y libertad en la filosofía de Alejandro Korn". En: [varios autores] Para la bistoria de las ideas argentinas, La Plata, Talleres Gráficos "El Sol", I952, pp. Ir-3I.

50. —- "Alejandro Korn, historiador del pensamiento argentino". Revista de la Universidad. Publicación de la Universidad Nacional de La Plata, La Plata, núm. I2, setiembre-diciembre I960, pp. I43-I 47 .

5I. GiUstr, Roberto F. "Un maestro: Alejandro Korn", Centro. Revista del Centro de Estudiantes de Filosofía y Letras, Buenos Aires, núm. 10, noviembre 1955, pp. 20-27.

52. GonzÁlez Martínez, Enrique. "A propósito de La libertad creadora" (Carta dirigida a Carlos Américo Amaya, 4 de marzo de 1924). Valoraciones, La Plata, tomo I, núm. 3, 1924, pp. 266267.

53. Insúa Rodríguez, Ramón. Historia de la filosofía en Hispanoamérica. Guayaquil, Imprenta de la Universidad, I945, PP. 197200.

54. IsusI, Alejandro de. "La casa en que escribió y murió Alejandro Korn". El Día, La Plata, 2 de diciembre de 1956.

55. IzQuierdo Ortega, Julián. "Metafísica y ética en el pensamiento de Alejandro Korn". Cuadernos Americanos, México, vol. CXV, núm. 2, marzo-abril I96r, pp. 97-rI4.

56. Jesualdo [Jesualdo Sosa]. "Alejandro Korn". En: Diecisiete educadores de América. Los constructores. Los reformadores, Montevideo, Ediciones Pueblos Unidos, I945, pp. 283-298.

57. Kemfr Mercado, Manfredo, Historia de la filosofía en Latinoamérica. Santiago de Chile, Zig-Zag, I958, 217 p.

58. KILGORE, William Jackson. Alejandro Korn's Interpretation of 
Creative Freedom. Baylor University, Waco, Texas, r958. 233 p. [Tesis].

59. "Alejandro Korn y la teoría relativista de los valores". Philosophia, Mendoza, núm. 23, r959, pp. 26-30.

60. - "Latin American Philosophy and the Place of Alejandro Korn". Journal of Inter-American Studies, vol. II, núm. I, January I960, PP. 77-82.

6r. KorN, Inés. "Alejandro Korn, mi padre". Universidad Nacional de Córdoba, Facultad de Filosofía y Humanidades, I960, to p. (Cuadernos de la Revisto de Humanidades). [Reproducido en $E l$ Panamá América, Panamá, 6 de febrero de Ig60].

62. Korn Villafañe, Adolfo. "Juan Vucetich y la alta cultura". Revista de Identificación y ciencias penales. La Plata, tomo XIX, núm. 74, I940-4r, pp. 43-45.

63. Larroyo, Francisco. "Deústua, Korn, Molina y Vaz Ferreira, en paralelo". Revista Mexicand de Filosofia, México, núm. I. [r958?], pp. $17-24$.

64. - "El centenario de Alejandro Korn, gran filósofo de nuestra América". La Gaceta, Publicación del Fondo de Cultura Económica, México, año VI, núm. 69, mayo 1960.

65. LIDA, Raimundo. "Korn, o el filósofo prudente". En: Alejandro KonN, Apuntes filosóficos. Buenos Aires, Editorial Claridad, $2^{3}$ ed. 1948, pp. 9-I4.

66. Lizaso, Félix. "La filosofía de Alejandro Korn". La Vanguardia, Buenos Aires, 29 de noviembre de I936. [Se comenta una conferencia radial de Lizaso y se transcriben párrafos. La conferencia fue publicada en Repertorio Americano, pero no se indica fecha].

67. López, Baldomero. "Filosofía y socialismo. A propósito de la publicación de las obras del doctor Alejandro Korn". Claridad, Buenos Aires, año XV, núm. 309, enero I,937.

68. Llavice, Rodolfo E. "Alejandro Korn, el filósofo". La Gaceta, Tucumán, 12 de diciembre de 1936.

69. Maliand, Ricardo G. "Límites y aportes del relativismo axiologico de Alejandro Korn". Revista de la Universidad, Publicación de la Universidad Nacional de La Plata; La Plata, núm. Ir, mayoagosto 1960, pp. 89-98. 
70. Malmierca Sánchez, Ennesto. Para una posición argentina. Notas a la filosofía de Alejandro Korn. Recopilación y comentarios de Ernesto Malmierca Sánchez. Edición de la Universidad Popular "Alejandro Korn". La Plata, I940, 45 P.

71. MAN, Wilhelm. "El fondo ideológico de las poesias de Alejandro Korn". Atenea, Concepción, Chile, año XXI, vol. IXXVII, núm. 232, octubre r944, pp. 90-99.

72. Mantonani, Juan, "Alejandro Korn. Bases para una filosofía de la educación". Revista de la Universidad. Publicación de la Universidad Nacional de La Plata, La Plata, núm. II, mayo-agosto I960, Pp. 99-II5.

73. Marinkev, Nicolás. "Forjadores platenses del espíritu universal". El Dia, La Plata, 3 de diciembre de r956.

74. MÁrquez, Angel D. "Ideas pedagógicas de Alejandro Korn". Cursos y Conferencias, Buenos Aires, año XV, vol. XXX, núm. I75-r76, octubre-noviembre I946, pp. 37-4I.

75. M. K. "Alejandro Korn, 'Las ideas filosóficas en la historia argentina' (Actividad, la Plata, julio igr6)". Revista de Filosofía, Buenos Aires, año II, núm. 5, septiembre I9I6, pp. 300-302. [Se trata de un comentario sobre el artículo de Korn].

76. M. P. E. "La preocupación religiosa de Alejandro Korn". Correo de la Tarde, Buenos Aires, 23 de octubre de 1959.

77. Orfila Reynal, Arnaldo. Alejandro Korn, argentino ejemplar. Conferencia pronunciada en el Colegio Libre de Estudios Superiores, filial Bahía Blanca, el 3 I de julio de 1942 , en el curso sobre Figuras Argentinas. Bahía Blanca, I943, 25 p.

78. Palacios, Alfredo. Espiritu y técnica en la Universidad. La Plata, Universidad Nacional de La Plata, I943, Cap. XIII, pp. 232-236.

79. Pex̃alver, P. "La filosofía en Hispanoamérica. Antecedentes y situación actual". Arbor. Revista General de Investigación y Cultura. Madrid, tomo XVII, núm. 57-58, setiembre-octubre r950, pp. $65-84$.

80. Pereira Alves, A. "Influencias filosóficas en la evolución maciowal, por Alejandro Korn". Cuba, Santa Clara (Cuba), I4 de julio de I937. [Publicado también en El Luchadior, Ciudad Bolívar (Venezuela), 26 de julio de 1937 ]. 
8r. —La libertad creadora, por Alejandro Korn". Cuba, Santa Clara (Cuba), Is de noviembre de I937. [Publicado también en El Lucbador, Ciudad Bolívar (Venezuela), 8 de octubre de I937].

82. Petronutr, Eduardo. Centenario del nacimiento de Alejandro Korn (1860-3 de mayo 1960). Sintesis cronológica de su vida y su obra. Separata del Almanaque Peuser del Mensajero, Buenos Aires, Peuser, r960, Is p.

83. Piccirilli, Ricardo, Romay, Francisco L. y Gianello, Leoncio. Diccionario bistórico argentino. Buenos Aires, Ediciones Históricas Argentinas, I954, tomo IV, p. 637.

84. PrÉrola, Raúl Alberto. "Alejandro Korn y el pensamiento contemporáneo". En Cursos y Conferencias, Buenos Aires, año XV, vol. XXX, octubre-noviembre I946, pp. 7-20. [Traducción inglesa de este ensayo se publicó en Pbilosopby and Phenomenological Research, vol. XIV, núm. 3, march I954, pp. 354-364, con el título de "Alejandro Korn and contemporary Philosophy"].

85. Poncio Ferrando, Angel. "Mi amigo el Director". En: Ana María R. de Aznar, Angel, Poncio Ferrando y María de VillariNo, Alejandro Korn. Tres testimonios. La Plata, Publicaciones de la Universidad Popular Alejandro Korn, r942, pp. 23-52. [Reproducido en: Angel Poncio Ferrando, Prosa y verso, La Plata, Edición de homenaje publicada por sus amigos, 1949, Pp. 37-53].

86. Pucciarelir, Eugenio. "Alejandro Korn, maestro de saber y de virtud". En: Alejandro KorN, La libertad creadora, Buenos Aires, Claridad, I937, pP. 5-22. [También en: Cursos y Conferencias, Buenos Aires, voil. $\mathrm{X}$, octubre 1936, pp. I067-I086].

87. - "La filosofía de Alejandro Korn". Congreso Internacional de Filosofía, São Paulo, I954. Anais, vol. III, Pp. II37-I I45.

88. - "La lección de Alejandro Korn". Revista de la Universidad de Buenos Aires, Buenos Aires, quinta época, año IV, núm. 4, octubre-diciembre I959, pp. 643-46.

89. - "Alejandro Korn y el pensamiento europeo". Revista de la Universidad. Publicación de la Universıdad Nacional de La Plata, La Plata, núm. I2, setiembre-diciembre I960, pp. 29-55.

90. Recaséns Siches, Luis. "El pensamiento filosófico, social, político y jurídico en Hispano-América". Revista Mexicana de Sociolo- 
gía, México, año VI, vol. VI, núm. I, enero-abril r944, pp. 85I2I,

9I. Reissig, Luis. "El Korn que yo conoci". En: Segundo A. TRI, Gabriel del Mazo, Luis ReIssig y José Luis Romero, Alejondro Konn. Publicaciones de la Universidad Popular Alejandro Korn, La Plata, r941, pp. 43-58.

92. R. E. L. "Edición popular de las Obras de Alejandro Korn". La Gaceta, Tucumán, I6 de enero de I937.

93. ReYes, Alfonso. "Alejandro Korn". La Vanguardia, Buenos Aires, II de octubre de 1936.

94. - "Korn y la filosofía argentina". Repertorio Americano, San José, Costa Rica, año XXI, núm. 882, tomo XXXVII, núm. 2, sábado 20 de enero de I940, pp. 24 y 26. [De El Nacional, México, D. F., I4 de noviembre de I939].

95. Rodríguez-AlcalÁ, Hugo. "Alexander Korn, Philosopher and citizen". Americas, Washington, D. C., Unión Panamericana, vol. VI, noviembre I954, pp. 20-23.

96. - "Apuntes para una biografía de Alejandro Korn (Años I860-I933)".Revista Iberoamericana, Iowa, vol. XXIII, núm. 46, julio-diciembre r958, pp. $433-448$.

97. —_. "Evocación de Alejandro Korn en Melchor Romero: 'El director por antonomasia': I897-1916". Asomante, San Juan, P. Rico, año XIV, vol. XIV, núm. 2, abril-junio I958, pP. 50-7I.

98. - "Razón y sentimiento en Alejandro Korn". En: Korn, Romero, Güiralde's, Unamuno, Ortega, literatura paraguaya y otros ensayos, México, Ediciones de Andrea, (Colección Studium, vol. r9), I958, pp. 9-29.

99. - "Alejandro Korn y el concepto de la Historia". En: Korn, Romero Güiraldes. .., edic cit., pp. 5I-59.

roo. - "El socratismo de Alejandro Korn". En: Korn, Romero, Gütraldes. ., edic. cit., pp. 3I-50.

ror. Rodríguez Bustamante, Norberto. "Los apuntes filosóficos de Korn'. Cursos y Conferenciass, Buenos Aires, año XV, vol. XXX, núm. I75-176, octubre-noviembre I946, pp. 21-24.

ro2. - Alejandro Korn y el problema de la cultura nacional. La Plata, Universidad Nacional de La Plata, (Cuadernos de Extensión Universitaria, 4) 1960, $57 \mathrm{p}$. 
ro3. Rodríguez Cometa, José A. "Preludios a una superación de $L d$ libertad creadora". Humanidades, Publicación de la Facultad de Humanidades y Ciencias de la Educación, Universidad Nacional de La Plata, La Plata, I930, pp. 209-225.

104. - "9 de octubre: presencia de Korn". Revista die la Universidad. Publicación de la Universidad Nacional de La Plata, La Plata, núm. I2, setiembre-diciembre I960, pp. I38-142.

I05. Romero, Francisco. "Alejandro Korn". [Palabras pronunciadas en el sepelio de Alejandro Korn]. Cursos y Conferencias, Buenos Aires, núm. 7, octubre I936, pp. 675-680.

ro6. - "Alejandro Korn (1860-1936)". Nosotros, Buenos Aires, $2^{\mathrm{a}}$ época, año I, núm. 8, noviembre 1936 , pp. 336-34r.

107. - "Un maestro argentino: Alejandro Korn". En: "Dos fragmentos sobre Alejandro Korn", Nosotros, Buenos Aires, $2^{7}$ época, año I, núm. 4, julio 1936, pp. 462-466.

I08. - - "Un testamento filosófico". Lat Gaceta, Tucumán, Iㅇ de enero de 1937 .

rog. - - "Alejandro Korn". En: Alejandro Korn, Filósofos y sistemas. Buenos Aires, Claridad, (Colección Claridad: "Obras de Alejandro Korn"), I937, Pp. 5-I4.

Iro. - "Alejandro Korn y el positivismo. Indicaciones para la historia de las ideas en la Argentina". II Congreso de Historia de Américut, vol. III, Buenos Aires, Academia Nacional de la Historia, I938, pp. 300-307.

III. - "Alejandto Korn (1860-1936)". En: Alejandro KorN, Obras, Universidad Nacional de la Plata, La Plata, I938, tomo I, pp. I-XXIX. [Reproducido en: Cursos y Conferencias, Buenos Aires, VI, octubre-noviembre 1937, núms. 7-8, pp. 71I-733; Francisco Romero, Luis Aznar, Angel Vassallo, Alejondro Korn, Buenos Aires, Losada, r940; Alejandro Korn, Obras completas, Buenos Aires, Claridad I949, pp. 9-26; Francisco Romero, Alejandro Korn, filósofo de la libertad, Buenos Aires, Reconstruir, 1957 (ver núm. I 20 de esta bibliografía].

II2. - "La vida y [la] obra de Alejandro Korn". La nueva Demo. cracia, XII, núm. 4, I939, pp. I7-20, pp. 3x-32; núm. 5, pp. I6-I8; núm. 6 , pp. $23-25$.

Ir3. - "Recuerdo de Alejandro Korn". La Vanguadia, Buenos Aires, 22 de octubre de 1939. [Reproducido en Repertorio de Honduras, Tegucigalpa, Honduras, IV, núm. 83, 1939, pp. 3-19] 
Ir4. —. "Tiempo y destiempo de Alejandto Korn". Verbum, Buenos Aires, núm. 2-3, I942, pp. 66-72. [Reproducido en: Libertad Creadora, La Plata-Buenos Aires, I, núm. 2, I943, Pp. 258-262; Cursos y Conferencias, Buenos Aites, año XV, vol. XXIX, núm. I72, julio I946, pp. 255-259; Filosofia de ayer $y$ de boy, Buenos Aires, Argos, I947; Alejandro Korn, filósofo de la libertad (véase el número I20 de esta Bibliografía) $]$.

II5. - - "Alejandro Korn". Cursos y Conferencias, Buenos Aires, año XV, vol. XXX, núm. I75-r76, octubre-noviembre 1946, pp. $\mathrm{I}-4$.

I16. —- "Tendencias contempotáneas en el pensamiento hispanoamericano". En: Sobre la filosofía en América, Buenos Aires, Editorial Raigal, (Problemas de la cultura en América, I), 1952, pp. I I-I8.

II7. -. "Indicaciones sobre la marcha del pensamiento filosófico hispanoamericano". En: Sobre la filosofía en América, edic. cit., Pp. r9-59.

II8. - "Filósofos latinoamericanos del siglo XX". En: Sobre la filosofía en América, edic. cit., p. 6r-70.

Ir9. - "Alejandro Korn en la vida y en la muerte". Cuadernos del Congreso por lat Libertad de la Cultura, París, núm. I3, julio-agosto I955, pp. 3-7. [Reproducido en Alejandro Korn, filósofo de la libertad (véase núm. I 20 de esta Bibliografía)].

120. - Alejandro Korn, filósofo de la libertad. Buenos Aires, Editorial Reconstruir, (Colección Radar. Serie: Manifestaciones de la ciencia, el arte y la literatura), 1956, 57 p. [Contiene: "Alejan. dro Korn (1860-1936)". "El testamento de un filósofo. Los Apuntes Filosóficos". "Tiempo y destiempo de Alejandro Korn". "Alejandro Korn en la vida y en la muerte"].

I2r. - "Sentido de la imposición del nombre de Alejandro Korn al Instituto de Filosofía". Revista de la Universidad de Buenos Aires, Buenos Aires, quinta época, año IV; núm. 4, octubre-diciembre r959, pp. 640-643.

I22. - "Personalidad y pensamiento de Alejandro Korn". Cuadernos del Congreso por la libentad de la Cultura, París, núm. 44, setiembre-octubre I960, PP. I3-I7.

123. Romero, Francisco y Romero, José Luis. Amérique Lafine. Estratto dal volume Les grands courants de la pensée mondiale con- 
temporaine. Panoramas nationaux, volume primo. Milan, Marzorati, [sin fecha].

I24. Romero, José Luis. "Experiencia y saber históricos en Alejandro Korn". En: Segundo A. TRI, Gabriel DEL MAzo, Luis ReIssig y José Luis Romero, Alejandro Korn, La Plata, Publicaciones de la Universidad Popular Alejandro Korn, I94x, pp. 6r-73.

I25. Rougés, Alberto. "Epístola filosófica". Valonaciones, La Plata, tomo 4, núm. I2, I928, pp. I78-I86.

126. - "Aproximación a Korn". En: "Dos fragmentos sobre Alejandro Korn". Nosotros, Buenos Aires, 2" época, año I, núm. 4, julio I936, pp. 460-462.

127. Ruzz, Enrique. "Engels, Ingenieros y Alejandro Korn". La Razón, Buenos Aires, 27 de julio de 1937.

28. SÁnchez Reulet, Aníbal. "Panorama de las ideas filosóficas en Hispanoamérica". Tierra Firme, Madrid, núm. 2, I936, pp. I8I-209.

r29. - "Un libro de Alejandro Korn". Nosotros, Buenos Aires, 2" época, año II, tomo III, núm. I2, marzo de I937, pp. 345-347.

rзo. —. "Alejandro Korn". Sur, Buenos Aires, año VII, núm. 28, enero de r937, pp. 87-92.

I3I. - - "Alejandro Kotn". En: La filosofía latinoamericana contemporánea. Washington, D. C., Unión Panamericana, (Pensamiento de América) I949, pp. 82-85.

32. Santillán, Diego A. de. Gran Enciclopedia Argentina. Buenos Aires, Ediar, I958, tomo IV, pp. 272-273.

133. ScIACcA, M. F. La filosofia, boy. De los origenes romanticos hasta los problemas actuales. Barcelona, Miracle, $3^{\mathrm{a}}$ edic., I96r, vol. II, cap. X: "La filosofía en Iberoamérica", pp. 488-490.

134. Soтo. Luis Emilio. "Apuntes filosófücos, del Dr. Korn". El País, Córdoba, 6 de octubre de 1935.

I35. Torchia-Estrada, Juan Carlos. La filosofía del siglo veinte, Buenos Aires, Atlántida, I955, 346 p.

136. —. "Los ensayos de Alejandro Korn sobre historia de la filosofía". En: Alejandro KorN, De San Agustin a Bergson. Buenos Aires, Editorial Nova, (Compendios Nova de iniciación cultural, 3I), I959, pp. 9-2I.

137. La filosofía en la Argentina. Washington, D. C., Unión Panamericana, (Pensamiento de América) I96r, pp. 249-26r. 
138. Tri, Segundo A. "Significación de Alejandro Korn". En: Segundo A. Tri, Gabriel Del Mazo, Luis Reissig y José Luis Romero, Alejandro Korn, La Plata, Publicaciones de la Universidad Popular Alejandro Korn, I94I, pp. I3-2I.

I39. Varios. "Homenaje al doctor Alejandro Korn". Humranidades, La Plata, I930, Pp. 309-3×2.

I40. Vassallo, Angel. "Presentación de Alejandro Korn, filósofo". En: Francisco Romero, L. AzNar, A. Vassallo, Alejandro Korn, Buenos Aires, Losada, I940, pp. 67-90.

r4r. - - "La filosofía de Alejandro Korn". Revista de la Universidad de Buenos Aires, Buenos Aires, $3^{7}$ época, año III, núm. 3, julio-setiembre 1945, pp. 5I-57.

I42. VázQuez, Juan Adolfo. "Fifty Years of Philosophy in Latin America". The Hibbert Journal, vol. XLIX, núm. 3, April x951, Pp. $291-296$.

I43. Villareal, Juan Manuel: "Alejandro Korn". La Nación, Buenos Aires, 3 de noviembre de 1957.

444. Villarino, María de. "Evolución de la vida cercana a Korn". En: Ana María R. de Aznar, Angel Poncio Ferrando y María VILlarino, Alejandro Korn. Tres testimonios, La Plata, Publicaciones de la Universidad Popular Alejandro Korn, 1942, pp. 55-72.

r45. Virasoro, Miguel Angel. "Alejandro Korn". En: Enciclopedia filosófica. Venezuela - Roma, Centro di Studi Filosofici di Gallarate, Istituto per la Collaborazione Culturale, 1957 ,II, p. I.735.

446. VirAsoro, Rafael. "Alejandro Korn en la evolución del pensamiento argentino". Universidad, Santa Fé, núm. 45, julio-setiembre 1960 , Pp. 5-33.

I47. Vitrer, Medardo. "La filosofía de don Alejandro Korn". Revista Cubana, La Habana, vol. XIV, julio-diciembre I940, Pp. I33-I42.

I48. WeINBERG, Gregorio. "Estudio preliminar". En: Alejandro KorN, El pensamiento argentino. Buenos Aires, Nova, 1961, pp. 7-22.

149. ZEA, Leopoldo. Dos etapas del pensamiento en Latinoamérica. Del Romanticismo al Positivismo. México, El Colegio de México, I949, $396 \mathrm{p}$.

J. C. T. E. 